Article

\title{
Synthesis and Antitumor Activity of 1-Substituted 1,2,3-Triazole-Mollugin Derivatives
}

\author{
Han Luo ${ }^{1,+}$, Yong-Feng $\mathrm{Lv}^{2,{ }^{\dagger}}$, Hong Zhang ${ }^{1}$, Jiang-Miao $\mathrm{Hu}^{2}{ }^{2}$, Hong-Mei $\mathrm{Li}^{2}$ and Shou-Jin Liu ${ }^{1, *}$ \\ 1 College of Pharmacy, Anhui University of Chinese Medicine, Hefei 230011, China; \\ luohan@stu.ahtcm.edu.cn (H.L.); zhanghong@ahtcm.edu.cn (H.Z.) \\ 2 State Key Laboratory of Phytochemistry and Plant Resources in West China, Kunming Institute of Botany, \\ Chinese Academy of Sciences, Kunming 650201, China; lvyongfeng@mail.kib.ac.cn (Y.-F.L.); \\ hujiangmiao@mail.kib.ac.cn (J.-M.H.); lihongmei@mail.kib.ac.cn (H.-M.L.) \\ * Correspondence: shjinliu@ahtcm.edu.cn or shjinliu@sina.com; Tel.: +86-139-5699-8502 \\ + Han Luo and Yong-Feng Lv contributed equally to this work.
}

check for updates

Citation: Luo, H.; Lv, Y.-F.; Zhang, H.; Hu, J.-M.; Li, H.-M.; Liu, S.-J. Synthesis and Antitumor Activity of 1-Substituted 1,2,3-Triazole-Mollugin Derivatives. Molecules 2021, 26, 3249. https://doi.org/10.3390/

molecules26113249

Academic Editor: Lucjan Strekowski

Received: 30 April 2021

Accepted: 26 May 2021

Published: 28 May 2021

Publisher's Note: MDPI stays neutral with regard to jurisdictional claims in published maps and institutional affiliations.

Copyright: (c) 2021 by the authors. Licensee MDPI, Basel, Switzerland. This article is an open access article distributed under the terms and conditions of the Creative Commons Attribution (CC BY) license (https:// creativecommons.org/licenses/by/ $4.0 /)$.

\begin{abstract}
A new series of mollugin-1,2,3-triazole derivatives were synthesized using a copper(I)catalyzed Huisgen 1,3-dipolar cycloaddition reaction of corresponding $O$-propargylated mollugin with aryl azides. All the compounds were evaluated for their cytotoxicity on five human cancer cell lines (HL-60, A549, SMMC-7721, SW480, and MCF-7) using MTS assays. Among the synthesized series, most of them showed cytotoxicity and most of all, compounds 14 and 17 exhibited significant cytotoxicity of all five cancer cell lines.
\end{abstract}

Keywords: mollugin; triazoles; antitumor activity; synthesis

\section{Introduction}

Mollugin, a methyl ester derivative of naphthoquinone extracted from the roots of Rubia Cordifolia [1,2], has been known have to broad spectrum of biological activities, including neuroprotective [3], anti-inflammatory [4,5], anti-bacterial [6], and antitumor activities [7-11]. In particular, mollugin displays indirect antitumor activity in various tumor models. For example:

(1) It can inhibit the secretion of hepatitis B surface antigen in human hepatocellular carcinoma Hep3B cells with $\mathrm{IC}_{50}=2.0 \mu \mathrm{g} / \mathrm{mL}$ [7].

(2) It can adjust the signal pathways of HER2/Akt/SREBP-1c to block the fatty acid synthase (FAS) gene expression, thus inhibits the human epidermal growth factor receptor 2 (HER2) gene expression of cancer cell proliferation and induces its apoptosis [8].

(3) It induces tumor cell apoptosis and autophagy through the PI3K/Akt/mTOR/p70S6K and extracellular regulated protein kinases (ERK) signaling pathways [9].

(4) It also significantly inhibits the expression of the NF- $\kappa$ B reporter gene which is induced by TNF- $\alpha$ in a dose-dependent manner to restrain tumor cell proliferation $[10,11]$.

Although mollugin has promising anticancer activity, it has little effect on the viability of cancer cells directly. Therefore, we tried to introduce new groups based on mollugin to enhance direct cytotoxicity of mollugin on cancer cells in the further investigation. Through literature research, we found that mollugin derivatives have been synthesized through modification of the ester group (C-2) and substitution reactions (C-4, C-6, C-7, C-1' and $\left.C-2^{\prime}\right)[12,13]$. To our surprise, the hydroxyl group (C-1) of mollugin has not been modified and we synthesized mollugin derivatives by modifying this group.

1,2,3-Triazoles are attractive connecting units, as they are stable with metabolic degradation and capable of hydrogen bonding, which can be favorable in binding of biomolecular targets and solubility [14,15]. Therefore, 1,2,3-Triazole is often used as a functional group that needs to be considered in the process of drug design [16,17]. In addition, the click 
reaction of copper(I)-catalyzed Huisgen 1,3-dipolar cycloaddition has been widely used to covalently link two molecular fragments between a terminal alkyne and an azide to generate substituted 1,2,3-triazoles [18,19]. It is worth mentioning that the reaction was generally regiospecific in forming only the 1,4-substituted 1,2,3-triazole, which facilitates the further purification of the target product $[20,21]$.

In this manuscript, the key intermediate was obtained by proparylation of the hydroxyl group (C-1) of mollugin (Figure 1). Then a series of mollugin derivatives were synthesized through the click chemistry approach by introducing different substituted aromatic azides [22-24]. Further the synthesized derivatives were screened for cytotoxicity against five different human cancer cell lines (HL-60, A549, SMMC-7721, SW480, and MCF-7).<smiles>COC(=O)c1c2c(c3ccccc3c1O)OC(C)(C)C=C2</smiles>

Figure 1. The structure of mollugin (1).

\section{Results and Discussion}

\subsection{Chemistry}

The key intermediate (3) was obtained as shown in Scheme 1. In the presence of potassium carbonate, treatment of mollugin (1) with 3-bromoprop-1-yne (2) in anhydrous DMF yielded the $O$-propargylated mollugin (3) in $85 \%$ yield $[25,26]$.<smiles>COC(=O)c1c2c(c3ccccc3c1O)OC(C)(C)C=C2</smiles>

1

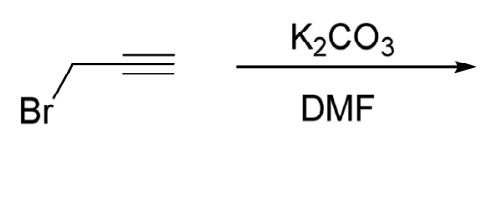

2<smiles>C#CCOc1c(C(=O)OC)c2c(c3ccccc13)OC(C)(C)C=C2</smiles>

Scheme 1. Preparation of O-propargylated mollugin (3).

The 1-substituted 1,2,3-triazole-mollugin derivatives were synthesized using a copper(I)catalyzed Huisgen 1,3-dipolar cycloaddition reaction of the corresponding O-propargylated mollugin (3) with different substituted aromatic azides (Scheme 2) [18,19]. In addition, all aromatic azides were prepared from corresponding boronic acid with sodium azide in the presence of $\mathrm{CuSO}_{4}$ in methanol $(\mathrm{MeOH})$ without further purification $[27,28]$.

As we can see from Scheme 2, 40 mollugin derivatives were obtained via the key click reaction. All the compounds present different substituents at the triazole moiety to evaluate their influence on the antitumor activity. Thus, mollugin derivatives with an aromatic ring with electron-donating groups or electron-withdrawing groups were prepared. All the synthesized triazolyl derivatives (5-44) were characterized by ${ }^{1} \mathrm{H} \mathrm{NMR},{ }^{13} \mathrm{C} N \mathrm{NR}$, and HRMS spectroscopic study (see Supplementary Materials). 
<smiles>C#CCOc1c(C(=O)OC)c2c(c3ccccc13)OC(C)(C)C=C2</smiles><smiles></smiles><smiles>[R]CC(C)c1ccc(C(C)(C)C)c(C(C)(C)C)c1</smiles>

Scheme 2. Preparation of 1-substituted 1,2,3-triazole-mollugin derivatives (5-44).

\subsection{Evaluation of Biological Activity}

Compound $\mathbf{1}$ and its synthesized derivatives were screened against a group of five different human cancer cell lines (HL-60, A549, SMMC-7721, SW480, and MCF-7) to evaluate their cytotoxic potential using MTS assay [29,30]. Cisplatin (DDP) and Taxol (TAX) were taken as reference drugs and their $\mathrm{IC}_{50}$ data were present in Table 1. More than half of the derivatives exhibited better cytotoxic activity than mollugin. 
Table 1. $\mathrm{IC}_{50}$ value in $\mu \mathrm{M}$ of mollugin and its derivatives on the panel of human cancer cell lines.

\begin{tabular}{|c|c|c|c|c|c|c|}
\hline & Tissue & Leukemia & Lung & Liver & Breast & Colon \\
\hline & Cell Line & HL-60 & A549 & SMMC-7721 & MCF-7 & SW480 \\
\hline No. & Compound & & & $\mathrm{IC}_{50}$ & & \\
\hline 1 & 1 & $>40$ & $>40$ & $>40$ & $>40$ & $>40$ \\
\hline 2 & 5 & $28.70 \pm 0.49$ & $>40$ & $19.28 \pm 1.48$ & $>40$ & $>40$ \\
\hline 3 & 6 & $>40$ & $>40$ & $24.28 \pm 1.47$ & $>40$ & $>40$ \\
\hline 4 & 7 & $>40$ & $>40$ & $33.96 \pm 0.93$ & $>40$ & $>40$ \\
\hline 5 & 8 & $>40$ & $>40$ & $>40$ & $>40$ & $>40$ \\
\hline 6 & 9 & $>40$ & $>40$ & $11.19 \pm 1.56$ & $27.71 \pm 1.06$ & $>40$ \\
\hline 7 & 10 & $>40$ & $>40$ & $>40$ & $>40$ & $>40$ \\
\hline 8 & 11 & $19.17 \pm 1.40$ & $>40$ & $12.97 \pm 1.52$ & $10.25 \pm 1.28$ & $>40$ \\
\hline 9 & 12 & $>40$ & $>40$ & $28.11 \pm 0.79$ & $>40$ & $>40$ \\
\hline 10 & 13 & $>40$ & $>40$ & $30.13 \pm 0.44$ & $>40$ & $>40$ \\
\hline 11 & 14 & $7.03 \pm 0.19$ & $5.12 \pm 0.01$ & $10.76 \pm 0.10$ & $13.91 \pm 0.51$ & $19.56 \pm 0.38$ \\
\hline 12 & 15 & $>40$ & $>40$ & $18.25 \pm 0.68$ & $29.80 \pm 0.84$ & $>40$ \\
\hline 13 & 16 & $35.21 \pm 2.66$ & $16.90 \pm 0.66$ & $18.33 \pm 0.18$ & $19.69 \pm 1.05$ & $26.79 \pm 0.89$ \\
\hline 14 & 17 & $16.38 \pm 0.47$ & $15.09 \pm 1.00$ & $12.61 \pm 0.80$ & $14.49 \pm 0.49$ & $17.40 \pm 0.91$ \\
\hline 15 & 18 & $11.00 \pm 0.12$ & $29.62 \pm 0.91$ & $12.06 \pm 0.59$ & $22.25 \pm 0.37$ & $33.42 \pm 0.64$ \\
\hline 16 & 19 & $10.50 \pm 0.02$ & $24.12 \pm 0.34$ & $12.98 \pm 0.54$ & $21.76 \pm 0.77$ & $33.77 \pm 0.54$ \\
\hline 17 & 20 & $25.07 \pm 0.49$ & $29.01 \pm 0.76$ & $13.02 \pm 0.84$ & $15.58 \pm 0.34$ & $25.59 \pm 1.70$ \\
\hline 18 & 21 & $21.76 \pm 0.27$ & $>40$ & $12.80 \pm 0.34$ & $22.50 \pm 1.14$ & $>40$ \\
\hline 19 & 22 & $>40$ & $>40$ & $32.25 \pm 0.83$ & $>40$ & $>40$ \\
\hline 20 & 23 & $>40$ & $>40$ & $>40$ & $>40$ & $>40$ \\
\hline 21 & 24 & $>40$ & $>40$ & $>40$ & $>40$ & $>40$ \\
\hline 22 & 25 & $>40$ & $>40$ & $27.84 \pm 0.54$ & $>40$ & $>40$ \\
\hline 23 & 26 & $>40$ & $>40$ & $>40$ & $>40$ & $>40$ \\
\hline 24 & 27 & $>40$ & $>40$ & $>40$ & $>40$ & $>40$ \\
\hline 25 & 28 & $>40$ & $>40$ & $>40$ & $21.74 \pm 1.06$ & $>40$ \\
\hline 26 & 29 & $>40$ & $>40$ & $17.89 \pm 0.27$ & $23.44 \pm 1.31$ & $>40$ \\
\hline 27 & 30 & $>40$ & $>40$ & $30.52 \pm 0.46$ & $>40$ & $>40$ \\
\hline 28 & 31 & $>40$ & $>40$ & $30.01 \pm 0.82$ & $>40$ & $>40$ \\
\hline 29 & 32 & $>40$ & $>40$ & $>40$ & $>40$ & $>40$ \\
\hline 30 & 33 & $>40$ & $>40$ & $31.56 \pm 0.51$ & $>40$ & $>40$ \\
\hline 31 & 34 & $>40$ & $>40$ & $>40$ & $>40$ & $>40$ \\
\hline 32 & 35 & $>40$ & $29.52 \pm 0.29$ & $>40$ & $>40$ & $>40$ \\
\hline 33 & 36 & $>40$ & $4.82 \pm 0.84$ & $21.66 \pm 0.89$ & $>40$ & $>40$ \\
\hline 34 & 37 & $>40$ & $>40$ & $>40$ & $>40$ & $>40$ \\
\hline 35 & 38 & $>40$ & $>40$ & $>40$ & $>40$ & $>40$ \\
\hline 36 & 39 & $>40$ & $>40$ & $>40$ & $>40$ & $>40$ \\
\hline 37 & 40 & $>40$ & $>40$ & $>40$ & $>40$ & $>40$ \\
\hline 38 & 41 & $>40$ & $>40$ & $>40$ & $>40$ & $>40$ \\
\hline 39 & 42 & $>40$ & $>40$ & $>40$ & $>40$ & $>40$ \\
\hline 40 & 43 & $>40$ & $>40$ & $>40$ & $>40$ & $>40$ \\
\hline 41 & 44 & $>40$ & $>40$ & $>40$ & $>40$ & $>40$ \\
\hline 42 & DDP & $1.312 \pm 0.024$ & $17.18 \pm 1.36$ & $19.97 \pm 0.26$ & $20.63 \pm 0.64$ & $15.50 \pm 0.99$ \\
\hline 43 & Taxol & $<0.008$ & $<0.008$ & $0.388 \pm 0.042$ & $<0.008$ & $<0.008$ \\
\hline
\end{tabular}

Some of derivatives displayed good cytotoxicity $\left(\mathrm{IC}_{50}<20 \mu \mathrm{M}\right)$ and even more potent than the control drug DDP, compounds 5, 9, 11, 14, 15, 16, 17, 18, 19, 20, 21 and 29 showed maximum inhibition effects against liver cancer cell line (SMMC-7721). Against the breast cancer cell line (MCF-7), compounds 11, 14, 16, 17, and 20 demonstrate cytotoxicity. Compounds 11, 14, 17, 218 and 19 displayed maximum inhibition effects against leukemia cells (HL-60). Compounds 14, 16, 17 and 36 displayed maximum inhibition effects against lung cancer cells (A549) whereas compounds $\mathbf{1 4}$ and $\mathbf{1 7}$ sensitized colon cancer cells (SW480) the most. Overall, the cytotoxicity of the derivatives was generally stronger than the parent molecule, the SMMC-7721 cell line was most sensitive to these compounds and 
compounds 14 and 17 exhibited significant inhibition effects against all the experimental cancer cell lines.

These data have allowed us to carry out a structure and activity relationship (SAR) study on the influence of the modifications of different group in the cytotoxicity. The main results can be summarized as follows: derivatives containing electron-donating groups such as hydroxyl, methoxy, and alcohol hydroxyl groups tend to have good cytotoxicity. By comparing $\mathrm{IC}_{50}$ value of compounds $5, \mathbf{1 1}, \mathbf{1 4}$, and 15, it could be concluded that cytotoxicity increased with the growth of methoxy group number in those derivatives. According to the experimental results, derivatives that contain electron-withdrawing groups do not have cytotoxicity except for compound 36. Compound 36 possesses notable cytotoxicity against $\mathrm{A} 549$ cancer cells with $\mathrm{IC}_{50}$ value of $4.82 \pm 0.84 \mu \mathrm{M}$, which is triple and quadruple improvement in cytotoxicity compared to the control drug DDP.

\section{Materials and Methods}

\subsection{General Experimental Procedures}

All the reagents and solvents used for purification and synthesis were purchased from Meryer. All synthesized derivatives were purified by column chromatography (silica gel, petroleum ether/ethyl acetate, 20:1 to 1:1 and petroleum ether/acetone, 20:1 to 1:1) and their structures were elucidated by ${ }^{1} \mathrm{H}$ NMR, ${ }^{13} \mathrm{C}$ NMR, high-resolution mass spectrometry (HR-ESIMS). Mass spectra were performed on UPLC-IT-TOF (Shimadzu, Kyoto, Japan) spectrometer. NMR spectra were recorded on AVANCE III $400 \mathrm{MHz}$ (Bruker, Bremerhaven, Germany) and Avance III $600 \mathrm{MHz}$ (Bruker, Bremerhaven, Germany) instruments using $\mathrm{CDCl}_{3}, \mathrm{CD}_{3} \mathrm{OD}$ or acetone- $d_{6}$ as the solvent with TMS as the internal standard. Chemical shifts $(\delta)$ were reported in parts per million (ppm) and the coupling constants $(J)$ were given in Hertz. Column chromatography was performed on silica gel (200-300 and 300-400 mesh, Qingdao Makall Group CO., Qingdao, China). All chemical reactions were monitored by TLC on silica gel 60 F254 plates and the spots were visualized by UV light and sprayed with $10 \% \mathrm{H}_{3} \mathrm{PO}_{4} \cdot 12 \mathrm{MoO}_{3}$ in $\mathrm{EtOH}$, followed by heating. All compounds were named using the ACD40 Name-Pro program, which is based on IUPAC rules. Azides (4) were synthesized according to procedures previously described in the literature $[27,28]$.

prop-1-yne-O-mollugin (3). To a solution of mollugin $(1.00 \mathrm{~g}, 3.52 \mathrm{mmol}, 1.0 \mathrm{eq})$ in DMF $(15 \mathrm{~mL})$ was added $\mathrm{K}_{2} \mathrm{CO}_{3}(725 \mathrm{mg}, 5.28 \mathrm{mmol}, 1.5 \mathrm{eq})$ slowly. The reaction mixture was stirred at rt for $15 \mathrm{~min}$, and propargyl bromide $(0.37 \mathrm{~mL}, 4.23 \mathrm{mmol}, 1.2 \mathrm{eq})$ was added dropwise at $\mathrm{rt}$. The reaction mixture was stirred at $\mathrm{rt}$ for $8 \mathrm{~h}$ before it was quenched by saturated $\mathrm{NH}_{4} \mathrm{Cl}$ aqueous solution $(20 \mathrm{~mL})$, and the mixture was extracted with ethyl acetate $(3 \times 20 \mathrm{~mL})$. The combined organic layer was washed with brine $(2 \times 40 \mathrm{~mL})$, and dried over $\mathrm{Na}_{2} \mathrm{SO}_{4}$, and filtered. After removal of the solvent under vacuum, the residue was purified by flash column chromatography on silica gel (12:1 to 8:1 petroleum ether/EtOAc) provided compound $3\left(964 \mathrm{mg}, 82 \%\right.$ yield) as a yellow solid, $\mathrm{R}_{\mathrm{f}}=0.3$ (petroleum ether $/$ EtOAc $=10: 1)[25]$.

\subsection{General Procedures for the Preparation of 1-Substituted 1,2,3-Triazole-Mollugin Derivatives}

To a solution of $0.2 \mathrm{mmol}$ of the corresponding azide in $3 \mathrm{~mL}$ mixed solution $\left(t-\mathrm{BuOH} / \mathrm{H}_{2} \mathrm{O}=1: 1, v / v\right)$ was added $O$-propargylated mollugin $(0.2 \mathrm{mmol})$, sodium ascorbate $(0.02 \mathrm{mmol}), \mathrm{CuSO}_{4} \cdot 5 \mathrm{H}_{2} \mathrm{O}(0.02 \mathrm{mmol})$. The reaction mixture was stirred for $48 \mathrm{~h}$ at room temperature before it was quenched by saturated $\mathrm{NH}_{4} \mathrm{Cl}$ aqueous solution $(4 \mathrm{~mL})$, and the mixture was extracted with ethyl acetate $(3 \times 6 \mathrm{~mL})$. The combined organic layer was washed with brine $(2 \times 15 \mathrm{~mL})$, and dried over $\mathrm{Na}_{2} \mathrm{SO}_{4}$, and filtered [31,32]. After removal of the solvent under vacuum, the residue was purified by flash column chromatography on silica gel (10/1 to 2/1 petroleum ether/EtOAc) provided compound 5-44.

1-O-((1-(4-methoxyphenyl)-1H-1,2,3-triazol)-4-yl)methyl)-mollugin (5). Yield: 89\%, yellow oil, ${ }^{1} \mathrm{H} \mathrm{NMR}\left(\mathrm{CDCl}_{3}, 400 \mathrm{MHz}\right) \delta 8.22(\mathrm{dd}, 1 \mathrm{H}, J=6.3,3.3 \mathrm{~Hz}), 8.17(\mathrm{dd}, 1 \mathrm{H}, J=6.3,3.3 \mathrm{~Hz})$, $8.01(\mathrm{~s}, 1 \mathrm{H}), 7.64(\mathrm{~d}, 2 \mathrm{H}, J=8.9 \mathrm{~Hz}), 7.52(\mathrm{~m}, 2 \mathrm{H}), 7.02(\mathrm{~d}, 2 \mathrm{H}, J=8.9 \mathrm{~Hz}), 6.44(\mathrm{~d}, 1 \mathrm{H}$, $J=9.9 \mathrm{~Hz}), 5.70(\mathrm{~d}, 1 \mathrm{H}, J=9.9 \mathrm{~Hz}), 5.32(\mathrm{~s}, 2 \mathrm{H}), 3.94(\mathrm{~s}, 3 \mathrm{H}), 3.86(\mathrm{~s}, 3 \mathrm{H}), 1.52(\mathrm{~s}, 6 \mathrm{H}) ;{ }^{13} \mathrm{C}$ 
$\mathrm{NMR}\left(\mathrm{CDCl}_{3}, 100 \mathrm{MHz}\right) \delta 167.6,159.9,145.9,145.4,144.7,130.5,130.3,127.9,127.2,127.1$, 126.8, 122.8, 122.5, 122.4, 76.6, 69.1, 55.7, 52.5, 27.7; ESIMS: $m / z 494$ [M+Na] ${ }^{+}$, HRESIMS: calcd for $\mathrm{C}_{27} \mathrm{H}_{25} \mathrm{~N}_{3} \mathrm{O}_{5} \mathrm{Na}[\mathrm{M}+\mathrm{Na}]^{+} 494.1688$, found 494.1686 .

1-O-((1-(4-methoxy-2-methylphenyl)-1H-1,2,3-triazol)-4-yl)methyl)-mollugin (6). Yield: $70 \%$, yellow solid, MP: $157-159{ }^{\circ} \mathrm{C},{ }^{1} \mathrm{H}$ NMR $\left(\mathrm{CDCl}_{3}, 400 \mathrm{MHz}\right) \delta 8.22(\mathrm{dd}, 1 \mathrm{H}, \mathrm{J}=6.4$, $3.3 \mathrm{~Hz}), 8.15(\mathrm{dd}, 1 \mathrm{H}, J=6.5,3.2 \mathrm{~Hz}), 7.72(\mathrm{~s}, 1 \mathrm{H}), 7.51(\mathrm{~m}, 2 \mathrm{H}), 7.23(\mathrm{~d}, 1 \mathrm{H}, J=8.5 \mathrm{~Hz})$, $6.84(\mathrm{~s}, 1 \mathrm{H}), 6.82(\mathrm{~d}, 1 \mathrm{H}, J=8.5 \mathrm{~Hz}), 6.44(\mathrm{~d}, 1 \mathrm{H}, J=10.0 \mathrm{~Hz}), 5.85(\mathrm{~d}, 1 \mathrm{H}, J=10.0 \mathrm{~Hz}), 5.34$ $(\mathrm{s}, 2 \mathrm{H}), 3.95(\mathrm{~s}, 3 \mathrm{H}), 3.84(\mathrm{~s}, 3 \mathrm{H}), 2.12(\mathrm{~s}, 3 \mathrm{H}), 1.52(\mathrm{~s}, 6 \mathrm{H}) ;{ }^{13} \mathrm{C} \mathrm{NMR}\left(\mathrm{CDCl}_{3}, 100 \mathrm{MHz}\right) \delta$ 167.6, 160.4, 145.7, 145.3, 143.6, 135.4, 130.3, 129.6, 128.1, 127.3, 127.1, 127.0, 126.7, 125.3, $122.9,122.4,121.2,119.9,116.3,112.4,111.8,76.6,68.9,55.6,52.5,27.7,18.0 ;$ ESIMS: $m / z 508$ $[\mathrm{M}+\mathrm{Na}]^{+}$, HRESIMS: calcd for $\mathrm{C}_{28} \mathrm{H}_{27} \mathrm{~N}_{3} \mathrm{O}_{5} \mathrm{Na}[\mathrm{M}+\mathrm{Na}]^{+} 508.1840$, found 508.1843.

1-(3-chloro-4-methoxyphenyl)-4-ethyl-1H-1,2,3-triazole-O-mollugin (7). Yield: 72\%, yellow solid, MP: $125-127{ }^{\circ} \mathrm{C},{ }^{1} \mathrm{H} \mathrm{NMR}\left(\mathrm{CDCl}_{3}, 400 \mathrm{MHz}\right) \delta 8.22(\mathrm{dd}, 1 \mathrm{H}, J=6.4,3.3 \mathrm{~Hz}), 8.14(\mathrm{dd}$, $1 \mathrm{H}, J=6.4,3.3 \mathrm{~Hz}), 8.00(\mathrm{~s}, 1 \mathrm{H}), 7.78(\mathrm{~d}, 1 \mathrm{H}, J=2.6 \mathrm{~Hz}), 7.60(\mathrm{dd}, 1 \mathrm{H}, J=8.9,2.6 \mathrm{~Hz}), 7.52$ $(\mathrm{m}, 2 \mathrm{H}), 7.03(\mathrm{~d}, 1 \mathrm{H}, J=8.9 \mathrm{~Hz}), 6.44(\mathrm{~d}, 1 \mathrm{H}, J=10.0 \mathrm{~Hz}), 5.70(\mathrm{~d}, 1 \mathrm{H}, J=10.0 \mathrm{~Hz}), 5.31$ $(\mathrm{s}, 2 \mathrm{H}), 3.96(\mathrm{~s}, 3 \mathrm{H}), 3.94(\mathrm{~s}, 3 \mathrm{H}), 1.52(\mathrm{~s}, 6 \mathrm{H}) ;{ }^{13} \mathrm{C} \mathrm{NMR}\left(\mathrm{CDCl}_{3}, 100 \mathrm{MHz}\right) \delta 167.6,155.4$, $145.7,145.4,144.9,130.5,130.3,127.9,127.2,127.1,126.8,123.6,123.1,122.7,122.5,121.7$, 121.1, 119.8, 112.4, 76.6, 69.0, 56.5, 52.5, 27.7; ESIMS: $m / z 528$ [M+Na] ${ }^{+}$, HRESIMS: calcd for $\mathrm{C}_{27} \mathrm{H}_{23} \mathrm{~N}_{3} \mathrm{O}_{5} \mathrm{ClNa}[\mathrm{M}+\mathrm{Na}]^{+}$528.1296, found 528.1297.

1-O-((1-(3-fluoro-4-methoxyphenyl)-1H-1,2,3-triazol)-4-yl)methyl)-mollugin (8). Yield: 78\%, yellow oil, ${ }^{1} \mathrm{H}$ NMR $\left(\mathrm{CDCl}_{3}, 400 \mathrm{MHz}\right) \delta 8.22(\mathrm{dd}, 1 \mathrm{H}, J=6.5,3.3 \mathrm{~Hz}), 8.14(\mathrm{dd}, 1 \mathrm{H}, J=6.5$, $3.2 \mathrm{~Hz}), 8.01(\mathrm{~s}, 1 \mathrm{H}), 7.52(\mathrm{~m}, 3 \mathrm{H}), 7.44(\mathrm{~m}, 1 \mathrm{H}), 7.07(\mathrm{t}, 1 \mathrm{H}, J=8.8 \mathrm{~Hz}), 6.44(\mathrm{~d}, 1 \mathrm{H}$, $J=9.9 \mathrm{~Hz}), 5.70(\mathrm{~d}, 1 \mathrm{H}, J=9.9 \mathrm{~Hz}), 5.32(\mathrm{~s}, 2 \mathrm{H}), 3.95(\mathrm{~s}, 3 \mathrm{H}), 3.94(\mathrm{~s}, 3 \mathrm{H}), 1.52(\mathrm{~s}, 6 \mathrm{H}) ;{ }^{13} \mathrm{C}$ $\mathrm{NMR}\left(\mathrm{CDCl}_{3}, 100 \mathrm{MHz}\right) \delta$ 167.6, 153.6, 151.1, 148.2, 145.7, 145.5, 144.9, 130.3, 127.9, 127.2, $127.1,126.8,122.7,122.5,121.7,121.1,119.8,116.6,113.8,112.4,109.9,76.6,69.0,56.5,52.5$, 27.7; ESIMS: $m / z 512$ [M+Na] ${ }^{+}$, HRESIMS: calcd for $\mathrm{C}_{27} \mathrm{H}_{24} \mathrm{~N}_{3} \mathrm{O}_{5} \mathrm{FNa}[\mathrm{M}+\mathrm{Na}]^{+} 512.1594$, found 512.1592 .

1-O-((1-(5-fluoro-2-methoxyphenyl)-1H-1,2,3-triazol)-4-yl)methyl)-mollugin (9). Yield: 48\%, yellow oil, ${ }^{1} \mathrm{H}$ NMR $\left(\mathrm{CDCl}_{3}, 400 \mathrm{MHz}\right) \delta 8.26(\mathrm{~s}, 1 \mathrm{H}), 8.22(\mathrm{dd}, 1 \mathrm{H}, J=6.4,3.3 \mathrm{~Hz}), 8.17(\mathrm{dd}$, $1 \mathrm{H}, J=6.4,3.3 \mathrm{~Hz}), 7.65(\mathrm{dd}, 1 \mathrm{H}, J=8.7,3.1 \mathrm{~Hz}), 7.52(\mathrm{~m}, 2 \mathrm{H}), 7.13(\mathrm{~m}, 1 \mathrm{H}), 7.03(\mathrm{~m}, 1 \mathrm{H})$, $6.44(\mathrm{~d}, 1 \mathrm{H}, J=9.9 \mathrm{~Hz}), 5.69(\mathrm{~d}, 1 \mathrm{H}, J=9.9 \mathrm{~Hz}), 5.33(\mathrm{~s}, 2 \mathrm{H}), 3.95(\mathrm{~s}, 3 \mathrm{H}), 3.88(\mathrm{~s}, 3 \mathrm{H}), 1.52$ $(\mathrm{s}, 6 \mathrm{H}) ;{ }^{13} \mathrm{C} \mathrm{NMR}\left(\mathrm{CDCl}_{3}, 100 \mathrm{MHz}\right) \delta 167.7,157.8,155.4,147.1,145.9,145.4,143.8,130.3$, 128.0, 127.1, 127.0, 126.8, 125.3, 122.9, 122.5, 121.1, 119.8, 116.2, 113.3, 112.7, 112.5, 76.6, 69.0, 56.6, 52.5, 27.7; ESIMS: $m / z 512$ [M+Na] ${ }^{+}$, HRESIMS: calcd for $\mathrm{C}_{27} \mathrm{H}_{24} \mathrm{~N}_{3} \mathrm{O}_{5} \mathrm{FNa}[\mathrm{M}+\mathrm{Na}]^{+}$ 512.1590 , found 512.1592 .

1-O-((1-(5-chloro-2-methoxyphenyl)-1H-1,2,3-triazol)-4-yl)methyl)-mollugin (10). Yield: 92\%, yellow solid, $\mathrm{MP}: 159-161{ }^{\circ} \mathrm{C},{ }^{1} \mathrm{H}$ NMR $\left(\mathrm{CDCl}_{3}, 400 \mathrm{MHz}\right) \delta 8.24-8.20(\mathrm{~m}, 2 \mathrm{H}), 8.17$ $(\mathrm{dd}, 1 \mathrm{H}, J=6.3,3.4 \mathrm{~Hz}), 7.86(\mathrm{~d}, 1 \mathrm{H}, J=2.6 \mathrm{~Hz}), 7.52(\mathrm{~m}, 2 \mathrm{H}), 7.38(\mathrm{dd}, 1 \mathrm{H}, J=8.9 \mathrm{~Hz}$, $2.6 \mathrm{~Hz}), 7.01(\mathrm{~d}, 1 \mathrm{H}, J=8.9 \mathrm{~Hz}), 6.44(\mathrm{~d}, 1 \mathrm{H}, J=9.9 \mathrm{~Hz}), 5.70(\mathrm{~d}, 1 \mathrm{H}, J=9.9 \mathrm{~Hz}), 5.33(\mathrm{~s}, 2 \mathrm{H})$, $3.95(\mathrm{~s}, 3 \mathrm{H}), 3.89(\mathrm{~s}, 3 \mathrm{H}), 1.52(\mathrm{~s}, 6 \mathrm{H}) ;{ }^{13} \mathrm{C} \mathrm{NMR}\left(\mathrm{CDCl}_{3}, 100 \mathrm{MHz}\right) \delta 167.7,149.6,145.9$, $145.4,143.8,130.3,129.7,128.0,127.1,127.0,126.9,126.8,126.3,125.3,122.9,122.5,121.1$, $119.8,113.4,112.4,76.6,69.1,56.4,52.5,27.7 ;$ ESIMS: $m / z 528$ [M+Na] ${ }^{+}$, HRESIMS: calcd for $\mathrm{C}_{27} \mathrm{H}_{24} \mathrm{~N}_{3} \mathrm{O}_{5} \mathrm{ClNa}[\mathrm{M}+\mathrm{Na}]^{+}$528.1296, found 528.1297.

1-O-((1-(3,5-dimethoxyphenyl) -1H-1,2,3-triazol)-4-yl)methyl)-mollugin (11). Yield: 84\%, yellow solid, MP: $51-53{ }^{\circ} \mathrm{C},{ }^{1} \mathrm{H}$ NMR $\left(\mathrm{CDCl}_{3}, 400 \mathrm{MHz}\right) \delta 8.22(\mathrm{dd}, 1 \mathrm{H}, J=6.4,3.5 \mathrm{~Hz})$, $8.16(\mathrm{dd}, 1 \mathrm{H}, J=6.4,3.5 \mathrm{~Hz}), 8.07(\mathrm{~s}, 1 \mathrm{H}), 7.52(\mathrm{~m}, 2 \mathrm{H}), 6.91(\mathrm{~d}, 2 \mathrm{H}, J=2.2 \mathrm{~Hz}), 6.51(\mathrm{t}, 1 \mathrm{H}$, $J=2.3 \mathrm{~Hz}), 6.44(\mathrm{~d}, 1 \mathrm{H}, J=9.9 \mathrm{~Hz}), 5.69(\mathrm{~d}, 1 \mathrm{H}, J=9.9 \mathrm{~Hz}), 5.32(\mathrm{~s}, 2 \mathrm{H}), 3.94(\mathrm{~s}, 3 \mathrm{H}), 3.85$ $(\mathrm{s}, 6 \mathrm{H}), 1.52(\mathrm{~s}, 6 \mathrm{H}) ;{ }^{13} \mathrm{C} \mathrm{NMR}\left(\mathrm{CDCl}_{3}, 100 \mathrm{MHz}\right) \delta 167.6,161.5,145.8,145.4,144.8,138.5$, 130.3, 127.9, 127.2, 127.1, 126.8, 122.7, 122.5, 121.7, 121.1, 119.9, 112.4, 100.7, 99.1, 76.6, 69.1, 55.7, 52.5, 27.7; ESIMS: $m / z 524[\mathrm{M}+\mathrm{Na}]^{+}$, HRESIMS: calcd for $\mathrm{C}_{28} \mathrm{H}_{27} \mathrm{~N}_{3} \mathrm{O}_{6} \mathrm{Na}[\mathrm{M}+\mathrm{Na}]^{+}$ 524.1793 , found 524.1792 .

1-O-((1-(benzo[d][1,3]dioxol-5-yl)-1H-1,2,3-triazol)-4-yl)methyl)-mollugin (12). Yield: 72\%, yellow solid, MP: $73-75^{\circ} \mathrm{C},{ }^{1} \mathrm{H}$ NMR $\left(\mathrm{CDCl}_{3}, 400 \mathrm{MHz}\right) \delta 8.22(\mathrm{dd}, 1 \mathrm{H}, J=6.5,3.3 \mathrm{~Hz})$, $8.15(\mathrm{dd}, 1 \mathrm{H}, J=6.5,3.3 \mathrm{~Hz}), 7.98(\mathrm{~s}, 1 \mathrm{H}), 7.52(\mathrm{~m}, 2 \mathrm{H}), 7.24(\mathrm{~d}, 1 \mathrm{H}, J=2.2 \mathrm{~Hz}), 7.14(\mathrm{dd}$, 
$1 \mathrm{H}, J=8.3,2.2 \mathrm{~Hz}), 6.90(\mathrm{~d}, 1 \mathrm{H}, J=8.3 \mathrm{~Hz}), 6.44(\mathrm{~d}, 1 \mathrm{H}, J=9.9 \mathrm{~Hz}), 6.06(\mathrm{~s}, 2 \mathrm{H}), 5.69(\mathrm{~d}$, $1 \mathrm{H}, J=9.9 \mathrm{~Hz}), 5.31(\mathrm{~s}, 2 \mathrm{H}), 3.94(\mathrm{~s}, 3 \mathrm{H}), 1.52(\mathrm{~s}, 6 \mathrm{H}) ;{ }^{13} \mathrm{C} \mathrm{NMR}\left(\mathrm{CDCl}_{3}, 100 \mathrm{MHz}\right) \delta 167.6$, 148.6, 148.1, 145.8, 145.4, 144.7, 131.5, 130.3, 127.9, 127.1, 127.1, 126.8, 122.8, 122.5, 121.9, $121.1,119.9,114.5,112.4,108.5,103.0,102.1,76.6,69.0,52.5,27.7$; ESIMS: $m / z 508$ [M+Na] ${ }^{+}$, HRESIMS: calcd for $\mathrm{C}_{27} \mathrm{H}_{23} \mathrm{~N}_{3} \mathrm{O}_{6} \mathrm{Na}[\mathrm{M}+\mathrm{Na}]^{+} 508.1474$, found 508.1479.

1-O-((1-(2,3-dihydrobenzo[b][1,4]dioxin-6-yl)-1H-1,2,3-triazol)-4-yl)methyl)-mollugin (13). Yield: $82 \%$, yellow solid, $\mathrm{MP}: 71-73^{\circ} \mathrm{C},{ }^{1} \mathrm{H} \mathrm{NMR}\left(\mathrm{CDCl}_{3}, 400 \mathrm{MHz}\right) \delta 8.22(\mathrm{dd}, 1 \mathrm{H}, J=6.4$, $3.3 \mathrm{~Hz}), 8.16(\mathrm{dd}, 1 \mathrm{H}, J=6.4,3.2 \mathrm{~Hz}), 7.98(\mathrm{~s}, 1 \mathrm{H}), 7.52(\mathrm{~m}, 2 \mathrm{H}), 7.27(\mathrm{~d}, 1 \mathrm{H}, J=2.6 \mathrm{~Hz})$, $7.17(\mathrm{dd}, 1 \mathrm{H}, J=8.7,2.6 \mathrm{~Hz}), 6.96(\mathrm{~d}, 1 \mathrm{H}, J=8.7 \mathrm{~Hz}) 6.42(\mathrm{~d}, 1 \mathrm{H}, J=9.9 \mathrm{~Hz}), 5.68(\mathrm{~d}, 1 \mathrm{H}$, $J=9.9 \mathrm{~Hz}), 4.29(\mathrm{~s}, 4 \mathrm{H}), 3.92(\mathrm{~s}, 3 \mathrm{H}), 1.52(\mathrm{~s}, 6 \mathrm{H}) ;{ }^{13} \mathrm{C} \mathrm{NMR}\left(\mathrm{CDCl}_{3}, 100 \mathrm{MHz}\right) \delta 167.6,145.8$, 145.3, 144.6, 144.1, 130.9, 130.3, 127.9, 127.1, 127.0, 126.8, 122.8, 122.5, 121.7, 121.1, 119.9, 118.1, 114.0, 112.4, 110.5, 76.6, 69.1, 64.4, 52.5, 27.7; ESIMS: $m / z 522[\mathrm{M}+\mathrm{Na}]^{+}$, HRESIMS: calcd for $\mathrm{C}_{28} \mathrm{H}_{25} \mathrm{~N}_{3} \mathrm{O}_{6} \mathrm{Na}[\mathrm{M}+\mathrm{Na}]^{+} 522.1638$, found 522.1636 .

1-O-((1-(3,4,5-trimethoxyphenyl)-1H-1,2,3-triazol)-4-yl)methyl)-mollugin (14). Yield: 76\%, yellow solid, MP: $55-57^{\circ} \mathrm{C},{ }^{1} \mathrm{H} \mathrm{NMR}\left(\mathrm{CDCl}_{3}, 400 \mathrm{MHz}\right) \delta 8.22(\mathrm{dd}, 1 \mathrm{H}, J=6.5,3.3 \mathrm{~Hz})$, $8.14(\mathrm{dd}, 1 \mathrm{H}, J=6.4,3.2 \mathrm{~Hz}), 8.03(\mathrm{~s}, 1 \mathrm{H}), 7.52(\mathrm{~m}, 2 \mathrm{H}), 6.95(\mathrm{~s}, 2 \mathrm{H}) 6.44(\mathrm{~d}, 1 \mathrm{H}, J=9.9 \mathrm{~Hz})$, $5.70(\mathrm{~d}, 1 \mathrm{H}, J=9.9 \mathrm{~Hz}), 5.33(\mathrm{~s}, 2 \mathrm{H}), 3.93(\mathrm{~s}, 9 \mathrm{H}), 3.89(\mathrm{~s}, 3 \mathrm{H}), 1.52(\mathrm{~s}, 6 \mathrm{H}) ;{ }^{13} \mathrm{C} \mathrm{NMR}\left(\mathrm{CDCl}_{3}\right.$, $100 \mathrm{MHz}) \delta 167.6,153.9,145.7,145.5,144.8,138.4,132.9,130.3,127.9,127.2,127.1,126.8$, 122.7, 122.5, 121.8, 121.3, 119.8, 112.4, 98.7, 76.6, 69.1, 61.1, 56.5, 52.5, 27.7; ESIMS: $m / z 554$ $[\mathrm{M}+\mathrm{Na}]^{+}$, HRESIMS: calcd for $\mathrm{C}_{29} \mathrm{H}_{29} \mathrm{~N}_{3} \mathrm{O}_{7} \mathrm{Na}[\mathrm{M}+\mathrm{Na}]^{+} 554.1899$, found 554.1898.

1-O-((1-(2,3,4-trimethoxyphenyl)-1H-1,2,3-triazol)-4-yl)methyl)-mollugin (15). Yield: 47\%, yellow solid, MP: $123-125{ }^{\circ} \mathrm{C},{ }^{1} \mathrm{H}$ NMR $\left(\mathrm{CDCl}_{3}, 400 \mathrm{MHz}\right) \delta 8.25-8.15(\mathrm{~m}, 2 \mathrm{H}), 8.07(\mathrm{~s}, 1 \mathrm{H})$, $7.52(\mathrm{~m}, 2 \mathrm{H}), 7.42(\mathrm{~d}, 2 \mathrm{H}, 9.0 \mathrm{~Hz}), 6.79(\mathrm{~d}, 1 \mathrm{H}, 9.0 \mathrm{~Hz}), 6.44(\mathrm{~d}, 1 \mathrm{H}, J=9.9 \mathrm{~Hz}), 5.69(\mathrm{~d}, 1 \mathrm{H}$, $J=9.9 \mathrm{~Hz}), 5.33(\mathrm{~s}, 2 \mathrm{H}), 3.97(\mathrm{~s}, 3 \mathrm{H}), 3.93(\mathrm{~s}, 3 \mathrm{H}), 3.93(\mathrm{~s}, 3 \mathrm{H}), 3.73(\mathrm{~s}, 3 \mathrm{H}), 1.52(\mathrm{~s}, 6 \mathrm{H}) ;{ }^{13} \mathrm{C}$ $\mathrm{NMR}\left(\mathrm{CDCl}_{3}, 100 \mathrm{MHz}\right) \delta 167.7,154.4,146.7,145.9,145.3,143.7,142.7,130.2,128.1,127.1$, 127.0, 126.8, 125.2, 124.5, 122.9, 122.4, 121.1, 120.1, 119.9, 112.4, 107.2, 76.5, 69.0, 61.6, 61.2, 56.2, 52.5, 27.7; ESIMS: $m / z 554$ [M+Na] ${ }^{+}$, HRESIMS: calcd for $\mathrm{C}_{29} \mathrm{H}_{29} \mathrm{~N}_{3} \mathrm{O}_{7} \mathrm{Na}[\mathrm{M}+\mathrm{Na}]^{+}$ 554.1898 , found 554.1898 .

1-O-((1-(2-hydroxyphenyl)-1H-1,2,3-triazol-4-yl)methyl)-O-mollugin (16). Yield: 67\%, white solid, MP: $183-185{ }^{\circ} \mathrm{C},{ }^{1} \mathrm{H}$ NMR $\left(\mathrm{CDCl}_{3}, 400 \mathrm{MHz}\right) \delta 9.59(\mathrm{~s}, 1 \mathrm{H}), 8.24(\mathrm{dd}, 1 \mathrm{H}, J=6.5$, $3.1 \mathrm{~Hz}), 8.14(\mathrm{~m}, 2 \mathrm{H}), 7.54(\mathrm{~m}, 2 \mathrm{H}), 7.42(\mathrm{dd}, 1 \mathrm{H}, J=8.1,1.6 \mathrm{~Hz}), 7.32(\mathrm{t}, 1 \mathrm{H}, J=7.1 \mathrm{~Hz}), 7.20$ $(\mathrm{dd}, 1 \mathrm{H}, J=8.3,1.4 \mathrm{~Hz}), 6.42(\mathrm{~d}, 1 \mathrm{H}, J=9.9 \mathrm{~Hz}), 5.70(\mathrm{~d}, 1 \mathrm{H}, J=9.9 \mathrm{~Hz}), 5.35(\mathrm{~s}, 2 \mathrm{H}), 3.93$ $(\mathrm{s}, 3 \mathrm{H}), 1.53(\mathrm{~s}, 6 \mathrm{H}) ;{ }^{13} \mathrm{C} \mathrm{NMR}\left(\mathrm{CDCl}_{3}, 100 \mathrm{MHz}\right) \delta 167.7,149.5,145.6,145.5,144.2,130.4$, 130.0, 127.7, 127.2, 127.1, 126.9, 123.0, 122.6, 122.5, 121.9, 121.2, 120.4, 120.4, 119.8, 119.4, 112.3, 76.6, 68.6, 52.7, 27.7; ESIMS: $m / z 456[\mathrm{M}-\mathrm{H}]^{-}$, HRESIMS: calcd for $\mathrm{C}_{26} \mathrm{H}_{23} \mathrm{~N}_{3} \mathrm{O}_{5} \mathrm{Na}$ $[\mathrm{M}-\mathrm{H}]^{-} 456.1569$, found 456.1565 .

1-O-((1-(3-hydroxyphenyl)-1H-1,2,3-triazol-4-yl)methyl)-mollugin (17). Yield: 55\%, white solid, MP: $182-184{ }^{\circ} \mathrm{C},{ }^{1} \mathrm{H}$ NMR $\left(\mathrm{CDCl}_{3}, 400 \mathrm{MHz}\right) \delta 9.44(\mathrm{~s}, 1 \mathrm{H}), 8.45(\mathrm{~s}, 1 \mathrm{H}), 8.24-8.13$ $(\mathrm{m}, 3 \mathrm{H}), 7.54(\mathrm{~m}, 2 \mathrm{H}), 7.36(\mathrm{t}, 1 \mathrm{H}, J=8.1 \mathrm{~Hz}), 7.07(\mathrm{dd}, 1 \mathrm{H}, J=7.9,2.0 \mathrm{~Hz}), 7.01(\mathrm{dd}, 1 \mathrm{H}$, $J=8.3,2.4 \mathrm{~Hz}), 6.44(\mathrm{~d}, 1 \mathrm{H}, J=9.9 \mathrm{~Hz}), 5.70(\mathrm{~d}, 1 \mathrm{H}, J=9.9 \mathrm{~Hz}), 5.35(\mathrm{~s}, 2 \mathrm{H}), 3.95(\mathrm{~s}, 3 \mathrm{H}), 1.53$ $(\mathrm{s}, 6 \mathrm{H}) ;{ }^{13} \mathrm{C} \mathrm{NMR}\left(\mathrm{CDCl}_{3}, 100 \mathrm{MHz}\right) \delta 167.7,158.6,145.7,145.5,144.6,137.5,130.6,130.3$, 127.8, 127.3, 127.1, 126.8, 122.6, 122.6, 121.6, 121.1, 119.8, 116.9, 112.4, 110.0, 109.0, 76.6, 68.6, 52.6, 27.7; ESIMS: $m / z 456[\mathrm{M}-\mathrm{H}]^{-}$, HRESIMS: calcd for $\mathrm{C}_{26} \mathrm{H}_{23} \mathrm{~N}_{3} \mathrm{O}_{5} \mathrm{Na}[\mathrm{M}-\mathrm{H}]^{-} 456.1569$, found 456.1565 .

1-O-((1-(4-hydroxyphenyl)-1H-1,2,3-triazol-4-yl)methyl)-mollugin (18). Yield: 51\%, yellow solid, MP: $209-211^{\circ} \mathrm{C},{ }^{1} \mathrm{H}$ NMR $\left(\left(\mathrm{CD}_{3}\right)_{2} \mathrm{CO}, 400 \mathrm{MHz}\right) \delta 8.90(\mathrm{~s}, 1 \mathrm{H}), 8.53(\mathrm{~s}, 1 \mathrm{H}), 8.27(\mathrm{~m}$, $1 \mathrm{H}), 8.21(\mathrm{~m}, 1 \mathrm{H}), 7.73(\mathrm{~d}, 2 \mathrm{H}, J=8.8 \mathrm{~Hz}), 7.60(\mathrm{~m}, 2 \mathrm{H}), 7.05(\mathrm{~d}, 2 \mathrm{H}, J=8.8 \mathrm{~Hz}), 6.46(\mathrm{~d}$, $1 \mathrm{H}, J=9.9 \mathrm{~Hz}), 5.85(\mathrm{~d}, 1 \mathrm{H}, J=9.9 \mathrm{~Hz}), 5.27(\mathrm{~s}, 2 \mathrm{H}), 3.97(\mathrm{~s}, 3 \mathrm{H}), 1.53(\mathrm{~s}, 6 \mathrm{H}) ;{ }^{13} \mathrm{C} \mathrm{NMR}$ $\left(\left(\mathrm{CD}_{3}\right)_{2} \mathrm{CO}, 100 \mathrm{MHz}\right) \delta 167.0,157.8,145.6,144.9,144.1,130.7,129.9,128.0,127.1,127.0$, $126.5,122.9,122.3,122.3,122.2,121.8,119.5,116.1,112.4,76.6,68.7,51.9,26.9 ;$ ESIMS: $\mathrm{m} / \mathrm{z}$ $456[\mathrm{M}-\mathrm{H}]^{-}$, HRESIMS: calcd for $\mathrm{C}_{26} \mathrm{H}_{23} \mathrm{~N}_{3} \mathrm{O}_{5} \mathrm{Na}[\mathrm{M}-\mathrm{H}]^{-}$456.1567, found 456.1565.

1-O-((1-(3-chloro-4-hydroxyphenyl)-1H-1,2,3-triazol-4-yl)methyl)-mollugin (19). Yield: 42\%, white solid, MP: $196-198^{\circ} \mathrm{C},{ }^{1} \mathrm{H}$ NMR $\left(\left(\mathrm{CD}_{3}\right)_{2} \mathrm{CO}, 400 \mathrm{MHz}\right) \delta 9.41(\mathrm{~s}, 1 \mathrm{H}), 8.63(\mathrm{~s}, 1 \mathrm{H}), 8.26$ $(\mathrm{m}, 1 \mathrm{H}), 8.22(\mathrm{~m}, 1 \mathrm{H}), 7.93(\mathrm{~d}, 1 \mathrm{H}, J=2.7 \mathrm{~Hz}), 7.75(\mathrm{dd}, 1 \mathrm{H}, J=8.8,2.7 \mathrm{~Hz}), 7.60(\mathrm{~m}, 2 \mathrm{H})$, 
$7.24(\mathrm{~d}, 1 \mathrm{H}, J=8.8 \mathrm{~Hz}), 6.46(\mathrm{~d}, 1 \mathrm{H}, J=9.9 \mathrm{~Hz}), 5.86(\mathrm{~d}, 1 \mathrm{H}, J=9.9 \mathrm{~Hz}), 5.27(\mathrm{~s}, 2 \mathrm{H}), 3.96(\mathrm{~s}$, $3 \mathrm{H}), 1.53(\mathrm{~s}, 6 \mathrm{H}) ;{ }^{13} \mathrm{C}$ NMR $\left(\left(\mathrm{CD}_{3}\right)_{2} \mathrm{CO}, 100 \mathrm{MHz}\right) \delta 167.0,153.4,145.5,144.9,144.3,130.7$, 130.3, 128.0, 127.1, 127.1, 126.5, 122.8, 122.5, 122.4, 122.2, 121.9, 120.9, 120.7, 119.5, 117.3, 112.4, 76.6, 68.6, 51.9, 26.9; ESIMS: $m / z 490$ [M-H] ${ }^{-}$, HRESIMS: calcd for $\mathrm{C}_{26} \mathrm{H}_{22} \mathrm{~N}_{3} \mathrm{O}_{5} \mathrm{ClNa}$ $[\mathrm{M}-\mathrm{H}]^{-}$490.1174, found 490.1175 .

1-O-((1-(3-(hydroxymethyl)phenyl)-1H-1,2,3-triazol-4-yl)methyl)-mollugin (20). Yield: 40\%, yellow solid, MP: $151-153{ }^{\circ} \mathrm{C},{ }^{1} \mathrm{H}$ NMR $\left(\mathrm{CDCl}_{3}, 400 \mathrm{MHz}\right) \delta 8.22(\mathrm{dd}, 1 \mathrm{H}, J=6.6,3.1 \mathrm{~Hz})$, $8.14(\mathrm{dd}, 1 \mathrm{H}, J=6.5,3.1 \mathrm{~Hz}), 8.10(\mathrm{~s}, 1 \mathrm{H}), 7.76(\mathrm{~s}, 1 \mathrm{H})), 7.62(\mathrm{dt}, 1 \mathrm{H}, J=8.0,1.5 \mathrm{~Hz}), 7.51$ $(\mathrm{m}, 2 \mathrm{H}), 7.46(\mathrm{t}, 1 \mathrm{H}, J=7.8 \mathrm{~Hz}), 7.40(\mathrm{~d}, 1 \mathrm{H}, J=7.7 \mathrm{~Hz}), 6.43(\mathrm{~d}, 1 \mathrm{H}, J=9.9 \mathrm{~Hz}), 5.69(\mathrm{~d}, 1 \mathrm{H}$, $J=9.9 \mathrm{~Hz}), 5.30(\mathrm{~s}, 2 \mathrm{H}), 4.78(\mathrm{~s}, 2 \mathrm{H}), 3.93(\mathrm{~s}, 3 \mathrm{H}), 1.52(\mathrm{~s}, 6 \mathrm{H}) ;{ }^{13} \mathrm{C} \mathrm{NMR}\left(\mathrm{CDCl}_{3}, 100 \mathrm{MHz}\right)$ $\delta$ 167.7, 145.8, 145.4, 144.8, 143.4, 137.1, 130.3, 129.8, 127.9, 127.2, 127.1, 127.0, 126.8, 122.7, 122.5, 121.6, 121.1, 119.8, 119.6, 118.9, 112.4, 76.6, 69.0, 64.3, 52.5, 27.7; ESIMS: $m / z 494$ [M+Na] ${ }^{+}$, HRESIMS: calcd for $\mathrm{C}_{27} \mathrm{H}_{25} \mathrm{~N}_{3} \mathrm{O}_{5} \mathrm{Na}[\mathrm{M}+\mathrm{Na}]^{+} 494.1686$, found 494.1686.

1-O-((1-(4-(hydroxymethyl)phenyl)-1H-1,2,3-triazol-4-yl)methyl)-mollugin (21). Yield: 40\%, yellow solid, MP: $194-196{ }^{\circ} \mathrm{C},{ }^{1} \mathrm{H}$ NMR $\left(\mathrm{CDCl}_{3}, 400 \mathrm{MHz}\right) \delta 8.22(\mathrm{dd}, 1 \mathrm{H}, J=6.2,3.3 \mathrm{~Hz})$, $8.15(\mathrm{dd}, 1 \mathrm{H}, J=6.1,3.3 \mathrm{~Hz}), 8.08(\mathrm{~s}, 1 \mathrm{H}), 7.71(\mathrm{~d}, 2 \mathrm{H}, J=8.0 \mathrm{~Hz}), 7.52(\mathrm{~m}, 4 \mathrm{H}), 6.43(\mathrm{~d}, 1 \mathrm{H}$, $J=9.9 \mathrm{~Hz}), 5.70(\mathrm{~d}, 1 \mathrm{H}, J=9.9 \mathrm{~Hz}), 5.32(\mathrm{~s}, 2 \mathrm{H}), 4.77(\mathrm{~s}, 2 \mathrm{H}), 3.94(\mathrm{~s}, 3 \mathrm{H}), 1.52(\mathrm{~s}, 6 \mathrm{H}) ;{ }^{13} \mathrm{C}$ NMR $\left(\mathrm{CDCl}_{3}, 100 \mathrm{MHz}\right) \delta 167.7,145.8,145.4,144.9,141.9,136.2,130.3,128.1,127.9,127.2$, 127.1, 126.8, 122.7, 122.5, 121.5, 121.1, 120.8, 119.8, 112.4, 76.6, 69.1, 64.4, 52.5, 27.7; ESIMS: $\mathrm{m} / \mathrm{z} 494[\mathrm{M}+\mathrm{Na}]^{+}$, HRESIMS: calcd for $\mathrm{C}_{27} \mathrm{H}_{25} \mathrm{~N}_{3} \mathrm{O}_{5} \mathrm{Na}[\mathrm{M}+\mathrm{Na}]^{+} 494.1684$, found 494.1686 .

1-O-((1-(2-ethylphenyl)-1H-1,2,3-triazol-4-yl)methyl)-mollugin (22). Yield: 45\%, yellow solid, MP: $73-75{ }^{\circ} \mathrm{C},{ }^{1} \mathrm{H}$ NMR $\left(\mathrm{CDCl}_{3}, 400 \mathrm{MHz}\right) \delta 8.21(\mathrm{dd}, 1 \mathrm{H}, J=6.5,3.3 \mathrm{~Hz}), 8.17(\mathrm{dd}$, $1 \mathrm{H}, J=6.4,3.2 \mathrm{~Hz}), 7.76(\mathrm{~s}, 1 \mathrm{H}), 7.52(\mathrm{~m}, 2 \mathrm{H}), 7.47(\mathrm{td}, 1 \mathrm{H}, J=7.4,1.6 \mathrm{~Hz}), 7.47(\mathrm{~d}, 1 \mathrm{H}$, $J=7.4 \mathrm{~Hz}), 7.34(\mathrm{td}, 1 \mathrm{H}, J=7.4,1.6 \mathrm{~Hz}), 7.47(\mathrm{dd}, 1 \mathrm{H}, J=8.0,1.6 \mathrm{~Hz}), 6.44(\mathrm{~d}, 1 \mathrm{H}, J=9.9 \mathrm{~Hz})$, $5.70(\mathrm{~d}, 1 \mathrm{H}, J=9.9 \mathrm{~Hz}), 5.36(\mathrm{~s}, 2 \mathrm{H}), 3.96(\mathrm{~s}, 3 \mathrm{H}), 2.46(\mathrm{q}, 2 \mathrm{H}, J=7.6 \mathrm{~Hz}), 1.52(\mathrm{~s}, 6 \mathrm{H}), 1.12(\mathrm{t}$, $3 \mathrm{H}, J=7.5 \mathrm{~Hz}) ;{ }^{13} \mathrm{C} \mathrm{NMR}\left(\mathrm{CDCl}_{3}, 100 \mathrm{MHz}\right) \delta 167.7,145.7,145.4,143.7,140.0,135.9,130.3$, 130.2, 129.8, 128.1, 127.1, 127.0, 126.7, 126.4, 125.3, 122.4, 121.1, 119.9, 112.4, 76.6, 68.9, 52.5, 27.7, 24.1, 15.0; ESIMS: $m / z 492[\mathrm{M}+\mathrm{Na}]^{+}$, HRESIMS: calcd for $\mathrm{C}_{28} \mathrm{H}_{27} \mathrm{~N}_{3} \mathrm{O}_{4} \mathrm{Na}[\mathrm{M}+\mathrm{Na}]^{+}$ 492.1893, found 492.1894 .

1-O-((1-(4-ethylphenyl)-1H-1,2,3-triazol-4-yl)methyl)-mollugin (23). Yield: 65\%, yellow solid, MP: $70-71{ }^{\circ} \mathrm{C},{ }^{1} \mathrm{H}$ NMR $\left(\mathrm{CDCl}_{3}, 400 \mathrm{MHz}\right) \delta 8.23(\mathrm{dd}, 1 \mathrm{H}, J=6.4,3.3 \mathrm{~Hz}), 8.17(\mathrm{dd}$, $1 \mathrm{H}, J=6.4,3.3 \mathrm{~Hz}), 8.06(\mathrm{~s}, 1 \mathrm{H}), 7.65(\mathrm{~d}, 2 \mathrm{H}, J=8.0 \mathrm{~Hz}), 7.53(\mathrm{~m}, 2 \mathrm{H}), 7.35(\mathrm{~d}, 2 \mathrm{H}, J=8.0 \mathrm{~Hz})$, $6.45(\mathrm{~d}, 1 \mathrm{H}, J=9.9 \mathrm{~Hz}), 5.70(\mathrm{~d}, 1 \mathrm{H}, J=9.9 \mathrm{~Hz}), 5.33(\mathrm{~s}, 2 \mathrm{H}), 3.95(\mathrm{~s}, 3 \mathrm{H}), 2.72(\mathrm{q}, 2 \mathrm{H}$, $J=7.6 \mathrm{~Hz}), 1.53(\mathrm{~s}, 6 \mathrm{H}), 1.28(\mathrm{t}, 3 \mathrm{H}, J=7.8 \mathrm{~Hz}) ;{ }^{13} \mathrm{C} \mathrm{NMR}\left(\mathrm{CDCl}_{3}, 100 \mathrm{MHz}\right) \delta 167.7,145.9$, 145.4, 145.3, 144.7, 134.9, 130.3, 129.1, 127.9, 127.2, 127.1, 126.8, 122.8, 122.5, 121.6, 121.1, 120.8, 119.9, 112.4, 76.6, 69.1, 52.5, 28.5, 27.7, 15.5; ESIMS: $\mathrm{m} / z$ $492[\mathrm{M}+\mathrm{Na}]^{+}$, HRESIMS: calcd for $\mathrm{C}_{28} \mathrm{H}_{27} \mathrm{~N}_{3} \mathrm{O}_{4} \mathrm{Na}[\mathrm{M}+\mathrm{Na}]^{+} 492.1896$, found 492.1894 .

1-O-((1-(4-vinylphenyl)-1H-1,2,3-triazol-4-yl)methyl)-mollugin (24). Yield: 45\%, yellow solid, MP: $67-69{ }^{\circ} \mathrm{C},{ }^{1} \mathrm{H}$ NMR $\left(\mathrm{CDCl}_{3}, 400 \mathrm{MHz}\right) \delta 8.23(\mathrm{dd}, 1 \mathrm{H}, J=6.3,3.3 \mathrm{~Hz}), 8.17(\mathrm{dd}$, $1 \mathrm{H}, J=6.3,3.3 \mathrm{~Hz}), 8.07(\mathrm{~s}, 1 \mathrm{H}), 7.72(\mathrm{~d}, 2 \mathrm{H}, 8.3 \mathrm{~Hz}), 7.56(\mathrm{~d}, 2 \mathrm{H}, 8.6 \mathrm{~Hz}), 8.53(\mathrm{~m}, 2 \mathrm{H})$, $6.76(\mathrm{dd}, 1 \mathrm{H}, J=17.6,10.9 \mathrm{~Hz}), 6.44(\mathrm{~d}, 1 \mathrm{H}, J=9.9 \mathrm{~Hz}), 5.83(\mathrm{~d}, 1 \mathrm{H}, J=17.6 \mathrm{~Hz}), 5.70(\mathrm{~d}$, $1 \mathrm{H}, J=9.9 \mathrm{~Hz}), 5.36(\mathrm{~d}, 1 \mathrm{H}, J=10.9 \mathrm{~Hz}), 5.34(\mathrm{~s}, 2 \mathrm{H}), 3.95(\mathrm{~s}, 3 \mathrm{H}), 1.53(\mathrm{~s}, 6 \mathrm{H}) ;{ }^{13} \mathrm{C} \mathrm{NMR}$ $\left(\mathrm{CDCl}_{3}, 100 \mathrm{MHz}\right) \delta 167.6,145.8,145.4,145.0,138.2,136.3,135.5,130.3,127.9,127.5,127.2$, 127.1, 126.8, 122.8, 122.5, 121.4, 121.1, 120.7, 119.9, 115.6, 112.4, 76.6, 69.1, 52.5, 27.7; ESIMS: $m / z 490[\mathrm{M}+\mathrm{Na}]^{+}$, HRESIMS: calcd for $\mathrm{C}_{28} \mathrm{H}_{25} \mathrm{~N}_{3} \mathrm{O}_{4} \mathrm{Na}[\mathrm{M}+\mathrm{Na}]^{+} 490.1737$, found 490.1737 .

1-O-((1-(3-(methylthio)phenyl)-1H-1,2,3-triazol-4-yl)methyl)-mollugin (25). Yield: 82\%, yellow solid, MP: $87-89^{\circ} \mathrm{C},{ }^{1} \mathrm{H}$ NMR $\left(\mathrm{CDCl}_{3}, 400 \mathrm{MHz}\right) \delta 8.23(\mathrm{dd}, 1 \mathrm{H}, J=6.2,3.5 \mathrm{~Hz}), 8.16$ $(\mathrm{dd}, 1 \mathrm{H}, J=6.6,3.1 \mathrm{~Hz}), 8.09(\mathrm{~s}, 1 \mathrm{H}), 7.64(\mathrm{t}, 1 \mathrm{H}, J=1.9 \mathrm{~Hz}), 7.53(\mathrm{~m}, 2 \mathrm{H}), 7.44(\mathrm{~m}, 1 \mathrm{H}), 7.40$ $(\mathrm{d}, 1 \mathrm{H}, J=7.9 \mathrm{~Hz}), 7.30(\mathrm{~d}, 1 \mathrm{H}, J=7.9 \mathrm{~Hz}), 6.44(\mathrm{~d}, 1 \mathrm{H}, J=9.9 \mathrm{~Hz}), 5.70(\mathrm{~d}, 1 \mathrm{H}, J=9.9 \mathrm{~Hz})$, $5.33(\mathrm{~s}, 2 \mathrm{H}), 3.94(\mathrm{~s}, 3 \mathrm{H}), 2.55(\mathrm{~s}, 3 \mathrm{H}), 1.52(\mathrm{~s}, 6 \mathrm{H}) ;{ }^{13} \mathrm{C} \mathrm{NMR}\left(\mathrm{CDCl}_{3}, 100 \mathrm{MHz}\right) \delta 167.6$, $145.8,145.4,145.0,141.4,137.5,130.3,129.9,127.9,127.2,127.1,126.8,126.4,122.7,122.5$, 121.6, 121.1, 119.9, 118.0, 116.9, 112.4, 76.6, 69.0, 52.6, 27.7, 15.5; ESIMS: $m / z 510[\mathrm{M}+\mathrm{Na}]^{+}$, HRESIMS: calcd for $\mathrm{C}_{27} \mathrm{H}_{25} \mathrm{~N}_{3} \mathrm{O}_{4} \mathrm{SNa}[\mathrm{M}+\mathrm{Na}]^{+} 510.1454$, found 510.1458 . 
1-O-((1-(dibenzo[b,d]thiophen-4-yl)-1H-1,2,3-triazol-4-yl)methyl)-mollugin (26). Yield: 40\%,

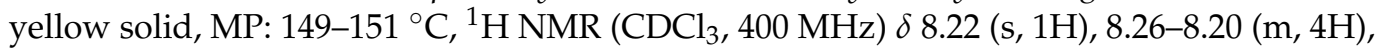
$7.95(\mathrm{~m}, 1 \mathrm{H}), 7.71(\mathrm{~d}, 1 \mathrm{H}, J=7.7 \mathrm{~Hz}), 7.62(\mathrm{~d}, 1 \mathrm{H}, J=7.7 \mathrm{~Hz}), 7.57-7.50(\mathrm{~m}, 4 \mathrm{H}), 6.46(\mathrm{~d}, 1 \mathrm{H}$, $J=9.9 \mathrm{~Hz}), 5.71(\mathrm{~d}, 1 \mathrm{H}, J=9.9 \mathrm{~Hz}), 5.41(\mathrm{~s}, 2 \mathrm{H}), 3.98(\mathrm{~s}, 3 \mathrm{H}), 1.54(\mathrm{~s}, 6 \mathrm{H}) ;{ }^{13} \mathrm{C} \mathrm{NMR}\left(\mathrm{CDCl}_{3}\right.$, $100 \mathrm{MHz}) \delta$ 167.7, 145.8, 145.5, 144.8, 140.2, 138.4, 134.8, 132.4, 132.2, 130.3, 128.0, 127.7, $127.2,127.1,126.8,125.2,124.9,122.8,122.8,122.5,122.4,121.9,121.8,121.2,119.9,119.5$, 112.4, 76.6, 69.0, 52.6, 27.7; ESIMS: $m / z 570$ [M+Na] $]^{+}$, HRESIMS: calcd for $\mathrm{C}_{32} \mathrm{H}_{25} \mathrm{~N}_{3} \mathrm{O}_{4} \mathrm{SNa}$ $[\mathrm{M}+\mathrm{Na}]^{+} 570.1457$, found 570.1458 .

1-O-((1-(4-isopropylphenyl)-1H-1,2,3-triazol-4-yl)methyl)-mollugin (27). Yield: 87\%, yellow solid, MP: 97-99 ${ }^{\circ} \mathrm{C},{ }^{1} \mathrm{H}$ NMR $\left(\mathrm{CDCl}_{3}, 400 \mathrm{MHz}\right) \delta 8.23$ (dd, 1H, J = 6.3, $\left.3.3 \mathrm{~Hz}\right), 8.17$ $(\mathrm{dd}, 1 \mathrm{H}, J=6.3,3.4 \mathrm{~Hz}), 8.06(\mathrm{~s}, 1 \mathrm{H}), 7.65(\mathrm{~d}, 2 \mathrm{H}, J=8.4 \mathrm{~Hz}), 7.53(\mathrm{~m}, 2 \mathrm{H}), 7.38(\mathrm{~d}, 2 \mathrm{H}$, $J=8.3 \mathrm{~Hz}), 6.44(\mathrm{~d}, 1 \mathrm{H}, J=9.9 \mathrm{~Hz}), 5.70(\mathrm{~d}, 1 \mathrm{H}, J=9.9 \mathrm{~Hz}), 5.33(\mathrm{~s}, 2 \mathrm{H}), 3.94(\mathrm{~s}, 3 \mathrm{H}), 2.99$ (hept, $1 \mathrm{H}, J=7.0 \mathrm{~Hz}), 1.53(\mathrm{~s}, 6 \mathrm{H}), 1.30(\mathrm{~s}, 3 \mathrm{H}), 1.29(\mathrm{~s}, 3 \mathrm{H}) ;{ }^{13} \mathrm{C} \mathrm{NMR}\left(\mathrm{CDCl}_{3}, 100 \mathrm{MHz}\right)$ $\delta 167.7,149.9,145.9,145.4,144.7,135.0,130.3,127.7,127.2,127.1,126.8,122.8,122.5,121.6$, 121.1, 120.8, 119.9, 112.4, 76.6, 69.1, 52.5, 33.9, 27.7, 23.9; ESIMS: $m / z 506$ [M+Na] ${ }^{+}$, HRESIMS: $^{2}$ calcd for $\mathrm{C}_{29} \mathrm{H}_{29} \mathrm{~N}_{3} \mathrm{O}_{4} \mathrm{Na}[\mathrm{M}+\mathrm{Na}]^{+}$506.2052, found 506.2050.

1-O-((1-(3-isopropylphenyl)-1H-1,2,3-triazol-4-yl)methyl)-mollugin (28). Yield: 60\%, yellow solid, MP: $55-57{ }^{\circ} \mathrm{C},{ }^{1} \mathrm{H}$ NMR $\left(\mathrm{CDCl}_{3}, 400 \mathrm{MHz}\right) \delta 8.23(\mathrm{dd}, 1 \mathrm{H}, J=6.3,3.3 \mathrm{~Hz}), 8.17$ $(\mathrm{dd}, 1 \mathrm{H}, J=6.3,3.3 \mathrm{~Hz}), 8.09(\mathrm{~s}, 1 \mathrm{H}), 7.63(\mathrm{~s}, 1 \mathrm{H}), 7.57-7.47(\mathrm{~m}, 3 \mathrm{H}), 7.44(\mathrm{t}, 1 \mathrm{H}, J=7.8 \mathrm{~Hz})$, $7.32(\mathrm{~d}, 1 \mathrm{H}, J=7.7 \mathrm{~Hz}), 6.45(\mathrm{~d}, 1 \mathrm{H}, J=9.9 \mathrm{~Hz}), 5.70(\mathrm{~d}, 1 \mathrm{H}, J=9.9 \mathrm{~Hz}), 5.34(\mathrm{~s}, 2 \mathrm{H}), 3.95$ $(\mathrm{s}, 3 \mathrm{H}), 1.53(\mathrm{~s}, 6 \mathrm{H}), 1.32(\mathrm{~s}, 3 \mathrm{H}), 1.30(\mathrm{~s}, 3 \mathrm{H}) ;{ }^{13} \mathrm{C}$ NMR $\left(\mathrm{CDCl}_{3}, 100 \mathrm{MHz}\right) \delta 167.6,151.0$, $145.9,145.4,144.8,137.1,130.3,129.7,128.0,127.1,127.1,127.0,126.8,122.8,122.5,121.7$, 121.1, 119.9, 119.1, 118.2, 112.4, 76.6, 69.2, 52.5, 34.2, 27.7, 23.9; ESIMS: $m / z 506[\mathrm{M}+\mathrm{Na}]^{+}$, HRESIMS: calcd for $\mathrm{C}_{29} \mathrm{H}_{29} \mathrm{~N}_{3} \mathrm{O}_{4} \mathrm{Na}[\mathrm{M}+\mathrm{Na}]^{+}$506.2050, found 506.2050.

1-O-((1-(3-(dimethylamino)phenyl)-1H-1,2,3-triazol-4-yl)methyl)-mollugin (29). Yield: 60\%, yellow solid, MP: $66-68{ }^{\circ} \mathrm{C},{ }^{1} \mathrm{H}$ NMR $\left(\mathrm{CDCl}_{3}, 400 \mathrm{MHz}\right) \delta 8.22(\mathrm{dd}, 1 \mathrm{H}, J=6.3,3.3 \mathrm{~Hz})$, $8.17(\mathrm{dd}, 1 \mathrm{H}, J=6.3,3.3 \mathrm{~Hz}), 8.07(\mathrm{~s}, 1 \mathrm{H}), 7.53(\mathrm{~m}, 2 \mathrm{H}), 7.34(\mathrm{t}, 1 \mathrm{H}, J=8.1 \mathrm{~Hz}), 7.10(\mathrm{t}$, $1 \mathrm{H}, J=2.3 \mathrm{~Hz}), 6.95(\mathrm{dd}, 1 \mathrm{H}, J=7.8,2.0 \mathrm{~Hz}), 6.76(\mathrm{dd}, 1 \mathrm{H}, J=8.5,2.5 \mathrm{~Hz}), 6.45(\mathrm{~d}, 1 \mathrm{H}$, $J=9.9 \mathrm{~Hz}), 5.70(\mathrm{~d}, 1 \mathrm{H}, J=9.9 \mathrm{~Hz}), 5.33(\mathrm{~s}, 2 \mathrm{H}), 3.95(\mathrm{~s}, 3 \mathrm{H}), 3.04(\mathrm{~s}, 6 \mathrm{H}), 1.53(\mathrm{~s}, 6 \mathrm{H}) ;{ }^{13} \mathrm{C}$ $\mathrm{NMR}\left(\mathrm{CDCl}_{3}, 100 \mathrm{MHz}\right) \delta 167.7,151.4,145.9,145.4,144.6,138.1,130.3,130.1,128.0,127.1$, 127.0, 126.8, 122.8, 122.5, 121.8, 121.1, 119.9, 112.5, 112.4, 108.1, 104.6, 76.6, 69.2, 52.5, 40.4, 27.7; ESIMS: $m / z 507[\mathrm{M}+\mathrm{Na}]^{+}$, HRESIMS: calcd for $\mathrm{C}_{28} \mathrm{H}_{28} \mathrm{~N}_{4} \mathrm{O}_{4} \mathrm{Na}[\mathrm{M}+\mathrm{Na}]^{+}$507.2001, found 507.2003.

1-O-((1-(2,3-dimethylphenyl)-1H-1,2,3-triazol-4-yl)methyl)-mollugin (30). Yield: 75\%, yellow solid, $\mathrm{MP}: 64-66{ }^{\circ} \mathrm{C},{ }^{1} \mathrm{H}$ NMR $\left(\mathrm{CDCl}_{3}, 400 \mathrm{MHz}\right) \delta 8.22-8.16(\mathrm{~m}, 2 \mathrm{H}), 7.73(\mathrm{~s}, 1 \mathrm{H}), 7.52$ $(\mathrm{m}, 2 \mathrm{H}), 7.30(\mathrm{~d}, 1 \mathrm{H}, J=7.6 \mathrm{~Hz}), 7.21(\mathrm{t}, 1 \mathrm{H}, J=7.7 \mathrm{~Hz}), 7.15(\mathrm{~d}, 1 \mathrm{H}, J=7.6 \mathrm{~Hz}), 6.45(\mathrm{~d}, 1 \mathrm{H}$, $J=9.9 \mathrm{~Hz}), 5.69(\mathrm{~d}, 1 \mathrm{H}, J=9.9 \mathrm{~Hz}), 5.36(\mathrm{~s}, 2 \mathrm{H}), 3.96(\mathrm{~s}, 3 \mathrm{H}), 2.36(\mathrm{~s}, 3 \mathrm{H}), 2.00(\mathrm{~s}, 3 \mathrm{H}), 1.52(\mathrm{~s}$, $6 \mathrm{H}) ;{ }^{13} \mathrm{C} \mathrm{NMR}\left(\mathrm{CDCl}_{3}, 100 \mathrm{MHz}\right) \delta 167.7,145.7,145.4,143.7,138.8,136.6,132.8,131.4,130.3$, 128.1, 127.1, 127.0, 126.7, 126.1, 125.3, 124.0, 122.9, 122.4, 121.2, 119.9, 112.4, 76.6, 68.9, 52.5, 27.7, 20.4, 14.3; ESIMS: $m / z 492$ [M+Na] ${ }^{+}$, HRESIMS: calcd for $\mathrm{C}_{28} \mathrm{H}_{27} \mathrm{~N}_{3} \mathrm{O}_{4} \mathrm{Na}[\mathrm{M}+\mathrm{Na}]^{+}$ 492.1896, found 492.1894 .

1-O-((1-(2,5-dimethylphenyl)-1H-1,2,3-triazol-4-yl)methyl)-mollugin (31). Yield: 58\%, yellow solid, MP: $59-61{ }^{\circ} \mathrm{C},{ }^{1} \mathrm{H}$ NMR $\left(\mathrm{CDCl}_{3}, 400 \mathrm{MHz}\right) \delta 8.33(\mathrm{dd}, 1 \mathrm{H}, J=6.5,3.3 \mathrm{~Hz}), 8.28$ $(\mathrm{dd}, 1 \mathrm{H}, J=6.5,3.3 \mathrm{~Hz}), 7.87(\mathrm{~s}, 1 \mathrm{H}), 7.64(\mathrm{~m}, 2 \mathrm{H}), 7.36(\mathrm{~m}, 2 \mathrm{H}), 6.57(\mathrm{~d}, 1 \mathrm{H}, J=9.9 \mathrm{~Hz}), 5.82$ $(\mathrm{d}, 1 \mathrm{H}, J=9.9 \mathrm{~Hz}), 5.47(\mathrm{~s}, 2 \mathrm{H}), 4.08(\mathrm{~s}, 3 \mathrm{H}), 2.50(\mathrm{~s}, 3 \mathrm{H}), 2.26(\mathrm{~s}, 3 \mathrm{H}), 1.64(\mathrm{~s}, 6 \mathrm{H}) ;{ }^{13} \mathrm{C} \mathrm{NMR}$ $\left(\mathrm{CDCl}_{3}, 100 \mathrm{MHz}\right) \delta 167.7,145.7,145.4,143.7,136.8,136.2,131.3,130.6,130.4,130.3,128.1$, 127.1, 127.0, 126.7, 126.5, 124.9, 122.9, 122.4, 121.2, 119.9, 112.4, 76.6, 68.9, 52.5, 27.7, 20.7, 21.1; ESIMS: $m / z 492[\mathrm{M}+\mathrm{Na}]^{+}$, HRESIMS: calcd for $\mathrm{C}_{28} \mathrm{H}_{27} \mathrm{~N}_{3} \mathrm{O}_{4} \mathrm{Na}[\mathrm{M}+\mathrm{Na}]^{+} 492.1896$, found 492.1894 .

1-O-((1-(3,4-dimethylphenyl)-1H-1,2,3-triazol-4-yl)methyl)-mollugin (32). Yield: 75\%, yellow solid, $\mathrm{MP}: 76-78{ }^{\circ} \mathrm{C},{ }^{1} \mathrm{H}$ NMR $\left(\mathrm{CDCl}_{3}, 400 \mathrm{MHz}\right) \delta 8.22(\mathrm{dd}, 1 \mathrm{H}, J=6.4,3.4 \mathrm{~Hz}), 8.17$ $(\mathrm{dd}, 1 \mathrm{H}, J=6.3,3.3 \mathrm{~Hz}), 8.04(\mathrm{~s}, 1 \mathrm{H}), 7.52(\mathrm{~m}, 3 \mathrm{H}), 7.43(\mathrm{dd}, 1 \mathrm{H}, J=8.0,3.3 \mathrm{~Hz}), 7.26(\mathrm{~d}, 1 \mathrm{H}$, $J=8.0 \mathrm{~Hz}), 6.45(\mathrm{~d}, 1 \mathrm{H}, J=10.0 \mathrm{~Hz}), 5.70(\mathrm{~d}, 1 \mathrm{H}, J=10.0 \mathrm{~Hz}), 5.33(\mathrm{~s}, 2 \mathrm{H}), 3.95(\mathrm{~s}, 3 \mathrm{H}), 2.35$ $(\mathrm{s}, 3 \mathrm{H}), 2.32(\mathrm{~s}, 3 \mathrm{H}), 1.53(\mathrm{~s}, 6 \mathrm{H}) ;{ }^{13} \mathrm{C} \mathrm{NMR}\left(\mathrm{CDCl}_{3}, 100 \mathrm{MHz}\right) \delta 167.6,145.9,145.4,144.7$, 
$138.4,137.6,135.0,130.7,130.3,128.0,127.1,127.0,126.8,122.8,122.5,121.9,121.5,121.1$, 119.9, 118.0, 112.4, 76.6, 69.2, 52.5, 27.7, 19.9, 19.5; ESIMS: $m / z 492$ [M+Na] ${ }^{+}$, HRESIMS: calcd for $\mathrm{C}_{28} \mathrm{H}_{27} \mathrm{~N}_{3} \mathrm{O}_{4} \mathrm{Na}[\mathrm{M}+\mathrm{Na}]^{+} 492.1896$, found 492.1894 .

1-O-((1-(5-fluoro-2-methylphenyl)-1H-1,2,3-triazol-4-yl)methyl)-mollugin (33). Yield: 65\%, white solid, MP: $61-63{ }^{\circ} \mathrm{C},{ }^{1} \mathrm{H}$ NMR $\left(\mathrm{CDCl}_{3}, 400 \mathrm{MHz}\right) \delta 8.21(\mathrm{dd}, 1 \mathrm{H}, \mathrm{J}=6.4,3.3 \mathrm{~Hz}), 8.15$ $(\mathrm{dd}, 1 \mathrm{H}, J=6.4,3.3 \mathrm{~Hz}), 7.76(\mathrm{~s}, 1 \mathrm{H}), 7.52(\mathrm{~m}, 2 \mathrm{H}), 7.32(\mathrm{dd}, 1 \mathrm{H}, J=8.2,5.9 \mathrm{~Hz}), 7.17-7.07$ $(\mathrm{m}, 2 \mathrm{H}), 6.44(\mathrm{~d}, 1 \mathrm{H}, J=9.9 \mathrm{~Hz}), 5.70(\mathrm{~d}, 1 \mathrm{H}, J=9.9 \mathrm{~Hz}), 5.35(\mathrm{~s}, 2 \mathrm{H}), 3.95(\mathrm{~s}, 3 \mathrm{H}), 2.16(\mathrm{~s}$, $3 \mathrm{H}), 1.52(\mathrm{~s}, 6 \mathrm{H}) ;{ }^{13} \mathrm{C} \mathrm{NMR}\left(\mathrm{CDCl}_{3}, 100 \mathrm{MHz}\right) \delta 167.6,162.0,159.6,145.5,143.9,132.7,136.9$, $130.3,129.3,128.0,127.1,127.1,126.8,124.9,122.8,122.5,121.2,119.8,116.9,113.5,112.4$, 76.6, 68.7, 52.6, 27.7, 17.4; ESIMS: $m / z 472[\mathrm{M}-\mathrm{H}]^{-}$, HRESIMS: calcd for $\mathrm{C}_{27} \mathrm{H}_{24} \mathrm{~N}_{3} \mathrm{O}_{4} \mathrm{FNa}$ $[\mathrm{M}-\mathrm{H}]^{-}$472.1675, found 472.1678 .

1-O-((1-(2-chloro-4-methylphenyl)-1H-1,2,3-triazol-4-yl)methyl)-mollugin (34). Yield: 92\%, yellow solid, $\mathrm{MP}: 55-57^{\circ} \mathrm{C},{ }^{1} \mathrm{H} \mathrm{NMR}\left(\mathrm{CDCl}_{3}, 400 \mathrm{MHz}\right) \delta 8.22(\mathrm{dd}, 1 \mathrm{H}, \mathrm{J}=6.5,3.4 \mathrm{~Hz})$, $8.16(\mathrm{dd}, 1 \mathrm{H}, J=6.5,3.3 \mathrm{~Hz}), 8.00(\mathrm{~s}, 1 \mathrm{H}), 7.51(\mathrm{~m}, 3 \mathrm{H}), 7.38(\mathrm{~s}, 1 \mathrm{H}), 7.23(\mathrm{~d}, 1 \mathrm{H}, J=8.0 \mathrm{~Hz})$, $6.44(\mathrm{~d}, 1 \mathrm{H}, J=9.9 \mathrm{~Hz}), 5.69(\mathrm{~d}, 1 \mathrm{H}, J=9.9 \mathrm{~Hz}), 5.35(\mathrm{~s}, 2 \mathrm{H}), 3.96(\mathrm{~s}, 3 \mathrm{H}), 2.42(\mathrm{~s}, 3 \mathrm{H}), 1.52$ $(\mathrm{s}, 6 \mathrm{H}) ;{ }^{13} \mathrm{C} \mathrm{NMR}\left(\mathrm{CDCl}_{3}, 100 \mathrm{MHz}\right) \delta 167.7,145.8,145.4,143.8,141.6,132.4,131.0,130.3$, 128.6, 128.3, 128.1, 127.5, 127.1, 127.0, 126.8, 125.5, 122.8, 122.4, 121.1, 119.9, 112.4, 76.6, 68.9, 52.6, 27.7, 21.1; ESIMS: $m / z 512$ [M+Na] ${ }^{+}$, HRESIMS: calcd for $\mathrm{C}_{27} \mathrm{H}_{24} \mathrm{~N}_{3} \mathrm{O}_{4} \mathrm{ClNa}[\mathrm{M}+\mathrm{Na}]^{+}$ 512.1343 , found 512.1348 .

1-O-((1-(4-chlorophenyl)-1H-1,2,3-triazol-4-yl)methyl)-mollugin (35). Yield: 20\%, white solid, MP: $160-162{ }^{\circ} \mathrm{C},{ }^{1} \mathrm{H} \mathrm{NMR}\left(\mathrm{CDCl}_{3}, 400 \mathrm{MHz}\right) \delta 8.23(\mathrm{dd}, 1 \mathrm{H}, J=6.5,3.3 \mathrm{~Hz}), 8.15$ $(\mathrm{dd}, 1 \mathrm{H}, J=6.5,3.3 \mathrm{~Hz}), 8.07(\mathrm{~s}, 1 \mathrm{H}), 7.71(\mathrm{~d}, 2 \mathrm{H}, J=8.7 \mathrm{~Hz}), 7.54-7.48(\mathrm{~m}, 4 \mathrm{H}), 6.44(\mathrm{~d}, 1 \mathrm{H}$, $J=9.9 \mathrm{~Hz}), 5.70(\mathrm{~d}, 1 \mathrm{H}, J=9.9 \mathrm{~Hz}), 5.33(\mathrm{~s}, 2 \mathrm{H}), 3.94(\mathrm{~s}, 3 \mathrm{H}), 1.53(\mathrm{~s}, 6 \mathrm{H}) ;{ }^{13} \mathrm{C} \mathrm{NMR}\left(\mathrm{CDCl}_{3}\right.$, $100 \mathrm{MHz}) \delta 167.8,145.9,145.7,145.4,135.8,134.9,130.5,130.2,128.0,127.4,127.3,127.0$, $122.9,122.8,122.1,121.7,121.3,120.0,112.6,76.8,69.2,52.7,27.9$; ESIMS: $m / z 498$ [M+Na] ${ }^{+}$, HRESIMS: calcd for $\mathrm{C}_{26} \mathrm{H}_{22} \mathrm{~N}_{3} \mathrm{O}_{4} \mathrm{ClNa}[\mathrm{M}+\mathrm{Na}]^{+} 498.1194$, found 498.1191 .

1-O-((1-(4-(trifluoromethyl)phenyl)-1H-1,2,3-triazol-4-yl)methyl)-mollugin (36). Yield: 15\%, white solid, MP: $168-170{ }^{\circ} \mathrm{C},{ }^{1} \mathrm{H} \mathrm{NMR}\left(\mathrm{CDCl}_{3}, 400 \mathrm{MHz}\right) \delta 8.23(\mathrm{dd}, 1 \mathrm{H}, J=6.5,3.3 \mathrm{~Hz}), 8.15$ $(\mathrm{m}, 2 \mathrm{H}), 7.93(\mathrm{~d}, 2 \mathrm{H}, J=8.4 \mathrm{~Hz}), 7.83(\mathrm{~d}, 2 \mathrm{H}, J=8.3 \mathrm{~Hz}), 7.54(\mathrm{~m}, 2 \mathrm{H}), 6.44(\mathrm{~d}, 1 \mathrm{H}, J=9.9 \mathrm{~Hz})$, $5.71(\mathrm{~d}, 1 \mathrm{H}, J=9.9 \mathrm{~Hz}), 5.35(\mathrm{~s}, 2 \mathrm{H}), 3.94(\mathrm{~s}, 3 \mathrm{H}), 1.53(\mathrm{~s}, 6 \mathrm{H}) ;{ }^{13} \mathrm{C} \mathrm{NMR}\left(\mathrm{CDCl}_{3}, 150 \mathrm{MHz}\right)$ $\delta 167.8,145.9,145.7,145.4,139.7,131.2,130.6,130.2,128.1,127.4,127.4,127.3,127.0,122.8$, 122.8, 122.1, 121.7, 121.6, 121.3, 120.9, 120.0, 112.6, 76.8, 69.1, 52.7, 27.9; ESIMS: $\mathrm{m} / z$ z 532 $[\mathrm{M}+\mathrm{Na}]^{+}$, HRESIMS: calcd for $\mathrm{C}_{27} \mathrm{H}_{22} \mathrm{~N}_{3} \mathrm{O}_{4} \mathrm{~F}_{3} \mathrm{Na}[\mathrm{M}+\mathrm{Na}]^{+} 532.1453$, found 532.1455 .

1-O-((1-(3-(trifluoromethoxy)phenyl)-1H-1,2,3-triazol-4-yl)methyl)-mollugin (37). Yield: $15 \%$, white solid, $\mathrm{MP}: 161-163{ }^{\circ} \mathrm{C},{ }^{1} \mathrm{H} \mathrm{NMR}\left(\mathrm{CDCl}_{3}, 400 \mathrm{MHz}\right) \delta 8.23(\mathrm{dd}, 1 \mathrm{H}, \mathrm{J}=6.5,3.3 \mathrm{~Hz})$, $8.15(\mathrm{dd}, 1 \mathrm{H}, J=6.4,3.3 \mathrm{~Hz}), 8.10(\mathrm{~s}, 1 \mathrm{H}), 7.75-7.66(\mathrm{~m}, 2 \mathrm{H}), 7.59(\mathrm{t}, 1 \mathrm{H}, J=8.1 \mathrm{~Hz}), 7.53(\mathrm{~m}$, $2 \mathrm{H}), 7.33(\mathrm{~d}, 1 \mathrm{H}, J=8.3 \mathrm{~Hz}), 6.44(\mathrm{~d}, 1 \mathrm{H}, J=9.9 \mathrm{~Hz}), 5.71(\mathrm{~d}, 1 \mathrm{H}, J=9.9 \mathrm{~Hz}), 5.34(\mathrm{~s}, 2 \mathrm{H}), 3.95$ $(\mathrm{s}, 3 \mathrm{H}), 1.53(\mathrm{~s}, 6 \mathrm{H}) ;{ }^{13} \mathrm{C} \mathrm{NMR}\left(\mathrm{CDCl}_{3}, 150 \mathrm{MHz}\right) \delta 167.8,150.2,145.9,145.7,145.6,138.3$, $131.4,130.5,128.1,127.4,127.3,127.0,122.9,122.8,121.7,121.3,121.2,120.0,118.9,113.9$, 112.6, 76.8, 69.2, 52.7, 27.9; ESIMS: $m / z 548$ [M+Na] ${ }^{+}$, HRESIMS: calcd for $\mathrm{C}_{27} \mathrm{H}_{22} \mathrm{~N}_{3} \mathrm{O}_{5} \mathrm{~F}_{3} \mathrm{Na}$ $[\mathrm{M}+\mathrm{Na}]^{+} 548.1401$, found 548.1404 .

1-O-((1-(4-(trifluoromethoxy)phenyl)-1H-1,2,3-triazol-4-yl)methyl)-mollugin (38). Yield: 20\%, white solid, MP: $157-159{ }^{\circ} \mathrm{C},{ }^{1} \mathrm{H}$ NMR $\left(\mathrm{CDCl}_{3}, 400 \mathrm{MHz}\right) \delta 8.23(\mathrm{dd}, 1 \mathrm{H}, J=6.4$, $3.3 \mathrm{~Hz}), 8.15(\mathrm{dd}, 1 \mathrm{H}, J=6.5,3.3 \mathrm{~Hz}), 8.08(\mathrm{~s}, 1 \mathrm{H}), 7.81(\mathrm{~d}, 2 \mathrm{H}, J=8.6 \mathrm{~Hz}), 7.53(\mathrm{~m}, 2 \mathrm{H})$, $7.40(\mathrm{~d}, 2 \mathrm{H}, J=8.4 \mathrm{~Hz}), 6.44(\mathrm{~d}, 1 \mathrm{H}, J=9.9 \mathrm{~Hz}), 5.70(\mathrm{~d}, 1 \mathrm{H}, J=9.9 \mathrm{~Hz}), 5.34(\mathrm{~s}, 2 \mathrm{H}), 3.94(\mathrm{~s}$, $3 \mathrm{H}), 1.53(\mathrm{~s}, 6 \mathrm{H}) ;{ }^{13} \mathrm{C} \mathrm{NMR}\left(\mathrm{CDCl}_{3}, 100 \mathrm{MHz}\right) \delta 167.6,149.1,145.7,145.5,145.3,135.4,130.3$, $127.9,127.2,127.1,126.8,122.7,122.6,122.3,122.2,121.6,121.1,119.8,112.4,76.6,69.0,52.5$, 27.7; ESIMS: $m / z 548$ [M+Na] ${ }^{+}$, HRESIMS: calcd for $\mathrm{C}_{27} \mathrm{H}_{22} \mathrm{~N}_{3} \mathrm{O}_{5} \mathrm{~F}_{3} \mathrm{Na}[\mathrm{M}+\mathrm{Na}]^{+} 548.1408$, found 548.1404 .

1-O-((1-(2,3-dichlorophenyl)-1H-1,2,3-triazol-4-yl)methyl)-mollugin (39). Yield: 70\%, yellow solid, MP: $66-68{ }^{\circ} \mathrm{C},{ }^{1} \mathrm{H}$ NMR $\left(\mathrm{CDCl}_{3}, 400 \mathrm{MHz}\right) \delta 8.21(\mathrm{dd}, 1 \mathrm{H}, J=6.4,3.3 \mathrm{~Hz}), 8.15$ $(\mathrm{dd}, 1 \mathrm{H}, J=6.3,3.3 \mathrm{~Hz}), 8.01(\mathrm{~s}, 1 \mathrm{H}), 7.63(\mathrm{dd}, 1 \mathrm{H}, J=8.1,1.6 \mathrm{~Hz}), 7.56-7.47(\mathrm{~m}, 3 \mathrm{H}), 7.38(\mathrm{t}$, $1 \mathrm{H}, J=8.1 \mathrm{~Hz}), 6.44(\mathrm{~d}, 1 \mathrm{H}, J=9.9 \mathrm{~Hz}), 5.69(\mathrm{~d}, 1 \mathrm{H}, J=9.9 \mathrm{~Hz}), 5.36(\mathrm{~s}, 2 \mathrm{H}), 3.96(\mathrm{~s}, 3 \mathrm{H})$, 1.52 (s, 6H); ${ }^{13} \mathrm{C} \mathrm{NMR}\left(\mathrm{CDCl}_{3}, 100 \mathrm{MHz}\right) \delta 167.6,145.6,145.4,143.9,136.4,134.6,131.7$, 
130.3, 128.2, 128.0, 127.9, 127.1, 127.0, 126.8, 126.3, 125.5, 122.8, 122.5, 121.2, 119.8, 112.4, 76.6, 68.7, 52.5, 27.7; ESIMS: $m / z 532[\mathrm{M}+\mathrm{Na}]^{+}$, HRESIMS: calcd for $\mathrm{C}_{26} \mathrm{H}_{21} \mathrm{~N}_{3} \mathrm{O}_{4} \mathrm{Cl}_{2} \mathrm{Na}[\mathrm{M}+\mathrm{Na}]^{+}$ 532.0802 , found 532.0801 .

1-O-((1-(3-chloro-4-fluorophenyl)-1H-1,2,3-triazol-4-yl)methyl)-mollugin (40). Yield: 30\%, white solid, MP: $179-181{ }^{\circ} \mathrm{C},{ }^{1} \mathrm{H}$ NMR $\left(\mathrm{CDCl}_{3}, 400 \mathrm{MHz}\right) \delta 8.23(\mathrm{dd}, 1 \mathrm{H}, J=6.4,3.4 \mathrm{~Hz}), 8.13$ $(\mathrm{dd}, 1 \mathrm{H}, J=6.4,3.3 \mathrm{~Hz}), 8.03(\mathrm{~s}, 1 \mathrm{H}), 7.86(\mathrm{dd}, 1 \mathrm{H}, J=6.3,2.7 \mathrm{~Hz}), 7.64(\mathrm{~m}, 1 \mathrm{H}), 7.53(\mathrm{~m}, 2 \mathrm{H})$, $7.31(\mathrm{t}, 1 \mathrm{H}, J=8.6 \mathrm{~Hz}), 6.44(\mathrm{~d}, 1 \mathrm{H}, J=9.9 \mathrm{~Hz}), 5.70(\mathrm{~d}, 1 \mathrm{H}, J=9.9 \mathrm{~Hz}), 5.33(\mathrm{~s}, 1 \mathrm{H}), 3.94(\mathrm{~s}$, $3 \mathrm{H}), 1.53(\mathrm{~s}, 6 \mathrm{H}) ;{ }^{13} \mathrm{C} \mathrm{NMR}\left(\mathrm{CDCl}_{3}, 100 \mathrm{MHz}\right) \delta 167.7,156.8,145.7,145.5,145.3,133.6,130.3$, 127.8, 127.2, 127.1, 126.8, 123.3, 122.7, 122.6, 121.6, 121.1, 120.5, 119.8, 117.8, 117.6, 112.4, 76.6, 68.9, 52.5, 27.7; ESIMS: $m / z 516$ [M+Na] ${ }^{+}$, HRESIMS: calcd for $\mathrm{C}_{26} \mathrm{H}_{21} \mathrm{~N}_{3} \mathrm{O}_{4} \mathrm{FCINa}[\mathrm{M}+\mathrm{Na}]^{+}$ 516.1096 , found 516.1097 .

1-O-((1-(3-chloro-5-(trifluoromethyl)phenyl)-1H-1,2,3-triazol-4-yl)methyl)-mollugin (41). Yield: $17 \%$, white solid, MP: $171-173{ }^{\circ} \mathrm{C},{ }^{1} \mathrm{H} \mathrm{NMR}\left(\mathrm{CDCl}_{3}, 400 \mathrm{MHz}\right) \delta 8.24(\mathrm{dd}, 1 \mathrm{H}$, $J=6.5,3.3 \mathrm{~Hz}), 8.16-8.08(\mathrm{~m}, 2 \mathrm{H}), 8.02(\mathrm{~m}, 1 \mathrm{H}), 7.94(\mathrm{~m}, 1 \mathrm{H}), 7.71(\mathrm{~s}, 1 \mathrm{H}), 7.54(\mathrm{~m}, 2 \mathrm{H})$, $6.44(\mathrm{~d}, 1 \mathrm{H}, J=9.9 \mathrm{~Hz}), 5.71(\mathrm{~d}, 1 \mathrm{H}, J=9.9 \mathrm{~Hz}), 5.35(\mathrm{~s}, 2 \mathrm{H}), 3.94(\mathrm{~s}, 3 \mathrm{H}), 1.53(\mathrm{~s}, 6 \mathrm{H}) ;{ }^{13} \mathrm{C}$ NMR $\left(\mathrm{CDCl}_{3}, 100 \mathrm{MHz}\right) \delta 167.8,145.9,145.8,138.4,136.9,134.1,133.8,130.6,128.0,127.4$, 127.3, 127.1, 125.9, 124.1, 122.8, 122.7, 121.6, 121.4, 120.0, 115.9, 112.6, 76.8, 69.1, 52.8, 29.9, 27.9; ESIMS: $m / z 566[\mathrm{M}+\mathrm{Na}]^{+}$, HRESIMS: calcd for $\mathrm{C}_{27} \mathrm{H}_{21} \mathrm{~N}_{3} \mathrm{O}_{4} \mathrm{~F}_{3} \mathrm{ClNa}[\mathrm{M}+\mathrm{Na}]^{+} 566.1066$, found 566.1065 .

1-O-((1-(3,5-bis(trifluoromethyl)phenyl)-1H-1,2,3-triazol-4-yl)methyl)-mollugin (42). Yield: 20\%, white solid, MP: $160-162{ }^{\circ} \mathrm{C},{ }^{1} \mathrm{H}$ NMR $\left(\mathrm{CDCl}_{3}, 400 \mathrm{MHz}\right) \delta 8.28-8.10(\mathrm{~m}, 3 \mathrm{H}), 8.19$ (s, $1 \mathrm{H}), 8.12(\mathrm{dd}, 1 \mathrm{H}, J=6.5,3.2 \mathrm{~Hz}), 7.97(\mathrm{~s}, 1 \mathrm{H}), 7.54(\mathrm{~m}, 2 \mathrm{H}), 6.44(\mathrm{~d}, 1 \mathrm{H}, J=9.9 \mathrm{~Hz}), 5.71$ $(\mathrm{d}, 1 \mathrm{H}, J=9.9 \mathrm{~Hz}), 5.36(\mathrm{~s}, 2 \mathrm{H}), 3.94(\mathrm{~s}, 3 \mathrm{H}), 1.53(\mathrm{~s}, 6 \mathrm{H}) ;{ }^{13} \mathrm{C} \mathrm{NMR}\left(\mathrm{CDCl}_{3}, 100 \mathrm{MHz}\right) \delta$ 167.6, 145.9, 145.6, 145.5, 138.0, 134.2, 133.8, 133.5, 133.2, 130.4, 127.8, 127.2, 127.1, 126.9, $123.9,122.6,122.5,122.3,121.4,121.2,120.6,119.8,112.4,76.6,68.7,52.5,27.7 ;$ ESIMS: $\mathrm{m} / \mathrm{z}$ $600[\mathrm{M}+\mathrm{Na}]^{+}$, HRESIMS: calcd for $\mathrm{C}_{28} \mathrm{H}_{21} \mathrm{~N}_{3} \mathrm{O}_{4} \mathrm{~F}_{6} \mathrm{Na}[\mathrm{M}+\mathrm{Na}]^{+} 600.1327$, found 600.1328.

1-O-((1-(4-cyanophenyl)-1H-1,2,3-triazol-4-yl)methyl)-mollugin (43). Yield: 47\%, white solid, MP: $167-169^{\circ} \mathrm{C},{ }^{1} \mathrm{H} \mathrm{NMR}\left(\mathrm{CDCl}_{3}, 400 \mathrm{MHz}\right) \delta 8.23(\mathrm{dd}, 1 \mathrm{H}, J=6.4,3.4 \mathrm{~Hz}), 8.17$ (s, $1 \mathrm{H}), 8.12(\mathrm{dd}, 1 \mathrm{H}, J=6.4,3.3 \mathrm{~Hz}), 7.92(\mathrm{~d}, 2 \mathrm{H}, J=8.7 \mathrm{~Hz}), 7.84(\mathrm{~d}, 2 \mathrm{H}, J=8.7 \mathrm{~Hz}), 7.53(\mathrm{~m}$, $2 \mathrm{H}), 6.43(\mathrm{~d}, 1 \mathrm{H}, J=9.9 \mathrm{~Hz}), 5.70(\mathrm{~d}, 1 \mathrm{H}, J=9.9 \mathrm{~Hz}), 5.34(\mathrm{~s}, 2 \mathrm{H}), 3.93(\mathrm{~s}, 3 \mathrm{H}), 1.53(\mathrm{~s}, 6 \mathrm{H}) ;{ }^{13} \mathrm{C}$ $\mathrm{NMR}\left(\mathrm{CDCl}_{3}, 100 \mathrm{MHz}\right) \delta 167.6,145.7,145.6,145.5,139.8,134.0,130.4,127.8,127.2,127.1$, 126.8, 122.6, 122.5, 121.2, 121.1, 120.7, 119.8, 117.8, 112.5, 112.4, 76.6, 68.8, 52.5, 27.7; ESIMS: $m / z 489$ [M+Na] $^{+}$, HRESIMS: calcd for $\mathrm{C}_{29} \mathrm{H}_{29} \mathrm{~N}_{3} \mathrm{O}_{4} \mathrm{Na}[\mathrm{M}+\mathrm{Na}]^{+} 489.1536$, found 489.1533 .

1-O-((1-(3-cyanophenyl)-1H-1,2,3-triazol-4-yl)methyl)-mollugin (44). Yield: 35\%, white solid, MP: $187-189{ }^{\circ} \mathrm{C},{ }^{1} \mathrm{H}$ NMR $\left(\mathrm{CDCl}_{3}, 400 \mathrm{MHz}\right) \delta 8.23(\mathrm{dd}, 1 \mathrm{H}, J=6.5,3.3 \mathrm{~Hz}), 8.12$ $8.20(\mathrm{~m}, 4 \mathrm{H}), 7.74(\mathrm{~d}, 1 \mathrm{H}, J=7.7 \mathrm{~Hz}), 7.67(\mathrm{t}, 1 \mathrm{H}, J=7.9 \mathrm{~Hz}), 7.53(\mathrm{~m}, 2 \mathrm{H}), 6.43(\mathrm{~d}, 1 \mathrm{H}$, $J=9.9 \mathrm{~Hz}), 5.71(\mathrm{~d}, 1 \mathrm{H}, J=9.9 \mathrm{~Hz}), 5.34(\mathrm{~s}, 2 \mathrm{H}), 3.94(\mathrm{~s}, 3 \mathrm{H}), 1.53(\mathrm{~s}, 6 \mathrm{H}) ;{ }^{13} \mathrm{C} \mathrm{NMR}\left(\mathrm{CDCl}_{3}\right.$, $100 \mathrm{MHz}) \delta$ 167.6, 145.6, 145.5, 137.6, 132.2, 130.9, 130.4, 127.8, 127.2, 127.1, 126.8, 124.6, $123.8,122.6,121.4,121.1,119.8,117.4,114.2,112.4,76.6,68.8,52.5,27.7$; ESIMS: $\mathrm{m} / z 489$ $[\mathrm{M}+\mathrm{Na}]^{+}$, HRESIMS: calcd for $\mathrm{C}_{27} \mathrm{H}_{22} \mathrm{~N}_{4} \mathrm{O}_{4} \mathrm{Na}[\mathrm{M}+\mathrm{Na}]^{+} 489.1532$, found 489.1533 .

\subsection{Biological Assays}

The following human cancer cell lines were used: HL-60, A-549, SMMC-7721, MCF-7, and SW-480. These cells were obtained from American type culture collection (ATCC) (Manassas, VA, USA). All the cells were cultured in RPMI-1640 or Dulbecco's modified Eagle medium (DMEM) medium (Biological Industries, Kibbutz Beit-Haemek, Israel), supplemented with $10 \%$ fetal bovine serum at $37^{\circ} \mathrm{C}$ in a humidified atmosphere with $5 \% \mathrm{CO}_{2}$. Cell viability was assessed by conducting colorimetric measurements of the amount of insoluble formazan formed in living cells based on the reduction of 3-(4,5-dimethylthiazol-2-yl)-5(3-carboxymethoxyphenyl)-2-(4-sulfophenyl)-2H-tetrazolium, inner salt (MTS) (Promega, Madison, WI, USA). Briefly, cells were seeded into each well of a 96-well cell culture plate. After $12 \mathrm{~h}$ of incubation at $37^{\circ} \mathrm{C}$, the test compound $(40 \mu \mathrm{M})$ was added. After incubated for $48 \mathrm{~h}$, cells were subjected to the MTS assay. Compounds with a growth inhibition rate of $50 \%$ were further evaluated at concentrations of $0.064,0.32,1.6,8$, and $40 \mu \mathrm{M}$ in triplicate, 
with cisplatin and paclitaxel (MeilunBio) as positive controls. After the incubation, MTS $(20 \mu \mathrm{L})$ was added to each well and the incubation continued for $4 \mathrm{~h}$ at $37^{\circ} \mathrm{C}$. After sufficient reaction, the light absorption value of each well was read by Multiskan FC at $492 \mathrm{~nm}$. The $\mathrm{IC}_{50}$ value of each compound was calculated with Reed and Muench's method.

\section{Conclusions}

In conclusion, 40 1-substituted 1,2,3-triazole-mollugin derivatives were synthesized through Huisgen 1,3-dipolar cycloaddition reaction and evaluated for cytotoxicity against a series of five different human cancer cell lines (HL-60, A549, SMMC-7721, SW480, and MCF-7) along with the parent molecule. Most of the derivatives showed better cytotoxicity than parent molecule. It is worth mentioning that our experiment results showed that compound $\mathbf{1 4}$ and $\mathbf{1 7}$ exhibited cytotoxicity of all five cancer cell lines significantly and compound 36 could enhance the cytotoxicity of lung cancer cells (A549) specifically. Structure and activity relationship (SAR) analysis reveals that electron-donating groups including hydroxyl, methoxy, and alcohol hydroxyl groups are essential for retaining the cytotoxicity to derivatives. In addition, for derivatives containing methoxy groups that the cytotoxicity may increase with the number of methoxy groups. Based on the SAR studies, we believe that the enhancement of cytotoxicity of the derivatives may be caused by the aromatic ring becoming electron-rich or the electron-donating atoms with lone pairs provided by electron-donating groups available to serve as hydrogen bond acceptors with the active site, which is worthy of further study.

Supplementary Materials: The following are available online. NMR spectra.

Author Contributions: Conceptualization, S.-J.L. and J.-M.H.; methodology, H.L. and Y.-F.L.; formal analysis, H.-M.L.; investigation, H.L.; data curation, H.L.; writing—original draft preparation, H.L.; writing-review and editing, H.Z.; supervision, S.J.L.; project administration, S.-J.L. All authors have read and agreed to the published version of the manuscript.

Funding: This research received no external funding.

Institutional Review Board Statement: Not applicable.

Informed Consent Statement: Not applicable.

Data Availability Statement: NMR spectra of synthesized compounds. See electronic Supplementary Information.

Acknowledgments: The authors thank the staff of analytical group and the staff of natural drug activity screening center of the State Key Laboratory of Phytochemistry and Plant Resources in West China, Kunming Institute of Botany, Chinese Academy of Sciences, for measurements of all spectra and the activity screening of all compounds.

Conflicts of Interest: The authors declare no conflict of interest.

Sample Availability: Samples of the compounds 5-44 are available from the authors.

\section{References}

1. Itokawa, H.; Mihara, K.; Takeya, K. Studies on a Novel Anthraquinone and Its Glycosides isolated from Rubia cordifolia and R. akane. Chem. Pharm. Bull. 1983, 31, 2353-2358. [CrossRef]

2. Son, J.K.; Jung, S.J.; Jung, J.H.; Fang, Z.; Lee, C.S.; Seo, C.S.; Moon, D.C.; Min, B.S.; Kim, M.R.; Woo, M.H. Anticancer Constituents from the Roots of Rubia cordifolia L. Chem. Pharm. Bull. 2008, 56, 213-216. [CrossRef]

3. Jeong, G.S.; Lee, D.S.; Kim, D.C.; Jahng, Y.; Son, J.K.; Lee, S.H.; Kim, Y.C. Neuroprotective and anti-inflammatory effects of mollugin via up-regulation of heme oxygenase-1 in mouse hippocampal and microglial cells. Eur. J. Pharmacol. 2011, 654, $226-234$. [CrossRef]

4. Zhu, Z.G.; Jin, H.; Yu, P.J.; Tian, Y.X.; Zhang, J.J; Wu, S.G. Mollugin Inhibits the Inflammatory Response in LipopolysaccharideStimulated RAW264.7 Macrophages by Blocking the Janus Kinase-Signal Transducers and Activators of Transcription Signaling Pathway. Biol. Pharm. Bull. 2013, 36, 399-406. [CrossRef] 
5. Zhang, Y.D.; Zhou, S.J.; Zhou, J.; Wanga, D.; Zhou, T. Regulation of NF-кB/MAPK signaling pathway attenuates the acute lung inflammation in Klebsiella pneumonia rats by mollugin treatment. Microb. Pathog. 2019, 132, 369-373. [CrossRef]

6. Idhayadhulla, A.; Xia, L.; Lee, Y.R.; Kim, S.H.; Wee, Y.J.; Lee, C.S. Synthesis of novel and diverse mollugin analogues and their antibacterial and antioxidant activities. Bioorg. Chem. 2014, 52, 77-82. [CrossRef]

7. Ho, L.K.; Don, M.J.; Chen, H.C.; Yeh, S.F.; Chen, J.M. Inhibition of Hepatitis B Surface Antigen Secretion on Human Hepatoma Cells. Components from Rubia cordifolia. J. Nat. Prod. 1996, 59, 330-333. [CrossRef]

8. Do, M.T.; Hwang, Y.P.; Kim, H.G.; Na, M.K.; Jeong, H.G. Mollugin inhibits proliferation and induces apoptosis by suppressing fatty acid synthase in HER2-overexpressing cancer cells. J. Cell. Physiol. 2013, 228, 1087-1097. [CrossRef]

9. Zhang, L.; Wang, H.; Zhu, J.; Xu, J.; Ding, K. Mollugin induces tumor cell apoptosis and autophagy via the PI3K/AKT/mTOR/p70S6K and ERK signaling pathways. Biochem. Biophys. Res. Commun. 2014, 450, 247-254. [CrossRef]

10. Zhe, W.; Ming, L.; Mi, C.; Ke, W.; Ma, J.; Jin, X. Mollugin Has an Anti-Cancer Therapeutic Effect by Inhibiting TNF- $\alpha$-Induced NF-кB Activation. Int. J. Mol. Sci. 2017, 18, 1619.

11. Kim, K.J.; Lee, J.S.; Kwak, M.K.; Choi, H.G.; Yong, C.S.; Kim, J.A.; Lee, Y.R.; Lyoo, W.S.; Park, Y.J. Anti-inflammatory action of mollugin and its synthetic derivatives in HT-29 human colonic epithelial cells is mediated through inhibition of NF- $\kappa \mathrm{B}$ activation. Eur. J. Pharmacol. 2009, 622, 52-57. [CrossRef]

12. Nishino, H.; Nakajima, Y.; Kakubari, Y.; Asami, N.; Deguchi, J.; Nugroho, A.E.; Hirasawa, Y.; Kaneda, T.; Kawasaki, Y.; Goda, Y.; et al. Syntheses and anti-inflammatory activity of azamollugin derivatives. Bioorg. Med. Chem. Lett. 2016, 26, 524-525. [CrossRef]

13. Hong, K.B.; Kim, D.; Kim, B.-K.; Woo, S.Y.; Lee, J.H.; Han, S.-H.; Bae, G.-U.; Kang, S. CF3-Substituted Mollugin 2-(4-Morpholinyl)ethyl ester as a Potential Anti-inflammatory Agent with Improved Aqueous Solubility and Metabolic Stability. Molecules 2018, 23, 2030. [CrossRef]

14. Horne, W.S.; Yadav, M.K.; Stout, C.D.; Ghadiri, M.R. Heterocyclic peptide backbone modifications in an alpha-helical coiled coil. J. Am. Chem. Soc. 2004, 126, 15366-15367. [CrossRef] [PubMed]

15. Vatmurge, N.S.; Hazra, B.G.; Pore, V.S.; Shirazi, F.; Chavan, P.S.; Deshpande, M.V. Synthesis and antimicrobial activity of beta-lactam-bile acid conjugates linked via triazole. Bioorg. Med. Chem. Lett. 2008, 18, 2043-2047. [CrossRef] [PubMed]

16. Agalave, S.G.; Maujan, S.R.; Pore, V.S. Click Chemistry: 1,2,3-Triazoles as Pharmacophores. Chem. Asian J. 2011, 6, $2696-2718$. [CrossRef] [PubMed]

17. Pingaew, R.; Mandi, P.; Nantasenamat, C.; Prachayasittikul, S.; Ruchirawat, S.; Prachayasittikul, V. Design, synthesis and molecular docking studies of novel N-benzenesulfonyl-1,2,3,4-tetrahydroisoquinoline-based triazoles with potential anticancer activity. Eur. J. Med. Chem. 2014, 81, 192-203. [CrossRef] [PubMed]

18. Rostovtsev, V.V.; Green, L.G.; Fokin, V.V.; Sharpless, K.B. A stepwise Huisgen cycloaddition process: Copper(I)-catalyzed regioselective "ligation" of azides and terminal alkynes. Angew. Chem. Int. Ed. 2002, 41, 2596-2599. [CrossRef]

19. Farooq, S.; Shakeel, U.R.; Hussain, A.; Hamid, A.; Qurishi, M.A.; Koul, S. Click chemistry inspired synthesis and bioevaluation of novel triazolyl derivatives of osthol as potent cytotoxic agents. Eur. J. Med. Chem. 2014, 84, 545-554. [CrossRef]

20. Tornoe, C.W.; Christensen, C.; Meldal, M. Peptidotriazoles on solid phase: 1,2,3 -triazoles by regiospecific copper(I)-catalyzed 1,3-dipolar cycloadditions of terminal alkynes to azides. J. Org. Chem. 2002, 67, 3057-3064. [CrossRef] [PubMed]

21. Totobenazara, J.; Burke, A.J. New click-chemistry methods for 1,2,3-triazoles synthesis: Recent advances and applications. Tetrahedron Lett. 2015, 56, 2853-2859. [CrossRef]

22. Rao, H.S.P.; Saha, A.; Vijjapu, S. Studies in the rearrangement reactions involving camphorquinone. RSC Adv. 2021, 11, 7180-7186. [CrossRef]

23. Dangroo, N.A.; Singh, J.; Dar, A.A.; Gupta, N.; Chinthakindi, P.K.; Kaul, A.; Khuroo, M.A.; Sangwan, P.L. Synthesis of alphasantonin derived acetyl santonous acid triazole derivatives and their bioevaluation for T and B-cell proliferation. Eur. J. Med. Chem. 2016, 120, 160-169. [CrossRef]

24. Gupta, N.; Qayum, A.; Raina, A.; Shankar, R.; Gairola, S.; Singh, S.; Sangwan, P.L. Synthesis and biological evaluation of novel bavachinin analogs as anticancer agents. Eur. J. Med. Chem. 2018, 145, 511-523. [CrossRef]

25. Lopez-Rojas, P.; Janeczko, M.; Kubinski, K.; Amesty, A.; Maslyk, M.; Estevez-Braun, A. Synthesis and Antimicrobial Activity of 4-Substituted 1,2,3-Triazole-Coumarin Derivatives. Molecules 2018, 23, 199. [CrossRef] [PubMed]

26. Zi, C.T.; Liu, Z.H.; Li, G.T.; Li, Y.; Zhou, J.; Ding, Z.T.; Hu, J.M.; Jiang, Z.H. Design, Synthesis, and Cytotoxicity of Perbutyrylated Glycosides of 4 $\beta$-Triazolopodophyllotoxin Derivatives. Molecules 2015, 20, 3255-3280. [CrossRef]

27. Clerc, A.; Bénéteau, V.; Pale, P.; Chassaing, S. Chan-Lam-type Azidation and One-Pot CuAAC under CuI-Zeolite Catalysis ChemCatChem 2020, 12, 2060-2065. [CrossRef]

28. Tao, C.Z.; Xin, C.; Li, J.; Liu, A.X.; Guo, Q.X. Copper-catalyzed synthesis of aryl azides and 1-aryl-1,2,3-triazoles from boronic acids. Tetrahedron Lett. 2007, 48, 3525-3529. [CrossRef]

29. Chi, X.-Q.; Zi, C.-T.; Li, H.-M.; Yang, L.; Lv, Y.-F.; Li, J.-Y.; Hou, B.; Ren, F.-C.; Hu, J.-M.; Zhou, J. Design, synthesis and structure-activity relationships of mangostin analogs as cytotoxic agents. RSC Adv. 2018, 8, 41377-41388. [CrossRef] 
30. Cory, A.H.; Owen, T.C.; Barltrop, J.A.; Cory, J.G. Use of an aqueous soluble tetrazolium/formazan assay for cell growth assays in culture. Cancer Commun. 1991, 3, 207-212. [CrossRef]

31. Silva, V.; Faria, B.D.; Colombo, E.; Ascari, L.; Freitas, G.; Flores, L.S.; Cordeiro, Y.; Romão, L.; Buarque, C.D. Design, synthesis, structural characterization and in vitro evaluation of new 1,4-disubstituted-1,2,3-triazole derivatives against glioblastoma cells. Bioorg. Chem. 2018, 83, 87-97. [CrossRef] [PubMed]

32. Phatak, P.S.; Bakale, R.D.; Kulkarni, R.S.; Dhumal, S.T.; Dixit, P.P.; Krishna, V.S.; Sriram, D.; Khedkar, V.M.; Haval, K.P. Design and synthesis of new indanol-1,2,3-triazole derivatives as potent antitubercular and antimicrobial agents. Bioorg. Med. Chem. Lett. 2020, 30, 127579. [CrossRef] [PubMed] 